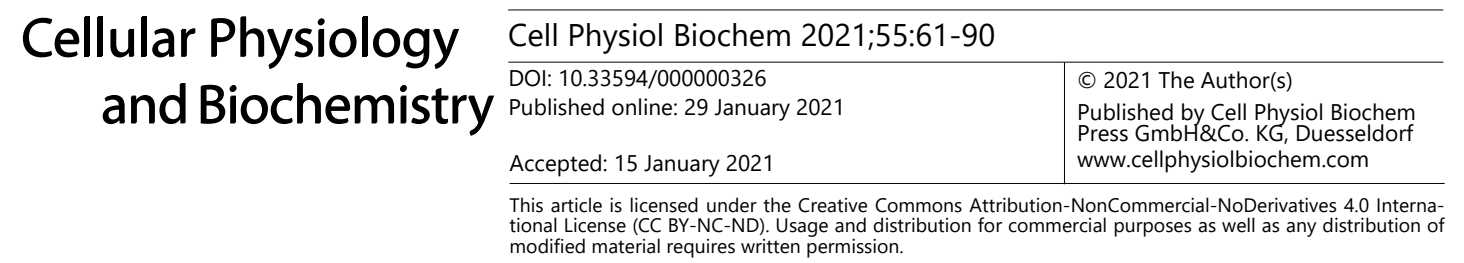

Review

\title{
Targeting Pancreatic Ductal Adenocarcinoma (PDAC)
}

\author{
Sofia Parrasia ${ }^{a}$ Mario Zorattia ${ }^{a, b}$ Ildikò Szabò ${ }^{b, c} \quad$ Lucia Biasutto $^{a, b}$

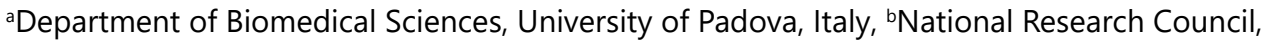 \\ Neuroscience Institute, Padova, Italy, 'Department of Biology, University of Padova, Italy
}

\section{Key Words}

Pancreatic Ductal Adenocarcinoma (PDAC) • Drug targeting • Stroma • Hypoxia • Peptides • Gemcitabine

\begin{abstract}
Pancreatic cancers are among the most ominous, and among the most studied. Their complexities have provided ample material for a huge investigative effort, which is briefly surveyed in this review. Eradication by surgery has proven extremely difficult, and a successful chemotherapeutic approach is desperately needed. Treatment with "traditional" anticancer drugs, such as benchmark gemcitabine or the current standard-of-care FOLFIRINOX quaternary combination increase the mean overall survival by only a few months and often leads to chemoresistance. Much work is therefore currently devoted to potentiating our pharmacological weapons by accurate targeting and, in particular, by acting on the dense tumoral stroma, a distinctive feature of PDAC accounting for much of the therapeutic difficulty. We give an overview of recent developments, touching on the major aspects of PDAC physiology and biochemistry, currently-used and experimental drugs, and targeting technologies under development. A few papers are discussed in some detail to help provide a sense of how the field is moving.

\section{Introduction - a brief overview of PDAC}

\section{Relevance}

Pancreatic malignancies are among those with the most discouraging prognosis: according to statistical data published by the National Cancer Institute the overall 5-year survival rate for the years 2010-2016 in the U.S. was 10.0\% (up from less than 3\% in 19751980) $[1,2]$. According to the statistics compiled by the International Agency for Cancer Research, in 2018 pancreatic cancers (PCs) accounted for $2.5 \%$ of all new cancer cases worldwide, and for $4.5 \%$ of all cancer-related deaths [3], making this disease the $14^{\text {th }}$ most common cancer, and the $7^{\text {th }}$-ranking killer. The incidence varies from country to country. Estimates for 2020 were that in the U.S. pancreatic cancers would newly affect 57,600
\end{abstract}




\section{Cellular Physiology Cell Physiol Biochem 2021;55:61-90 \\ \begin{tabular}{ll|l} 
and Biochemistry & $\begin{array}{l}\text { DOI: } 10.33594 / 000000326 \\
\text { Published online: } 29 \text { January } 2021\end{array}$ & $\begin{array}{l}\text { C } 2021 \text { The Author(s). Published by } \\
\text { Cell Physiol Biochem Press GmbH\&Co. KG }\end{array}$ \\
\hline
\end{tabular} \\ Parrasia et al.: Targeting PDAC}

persons and cause 47,050 deaths accounting for $3.2 \%$ of new cancer diagnoses, and for $7.8 \%$ of all cancer deaths [4]. These percentages have been increasing. Between 1973 and 2014 in the U.S. incidence has increased by about $1 \%$ each year [5], and projections published in 2014 envision pancreatic cancers becoming the second leading cause of cancer-related mortality before $2030[1,6]$.

\section{Treatment}

Surgical resection followed by adjuvant chemotherapy (which helps; e.g.: [7]) is the only potentially curative treatment available, but resection is often made difficult by factors such as vascular involvement and boundary fuzzyness. In the U.S. and elsewhere $80-85 \%$ of patients are found to have unresectable and/or already metastasized cancer at diagnosis [1]. The only treatments for unresectable cancers are radiotherapy or radiotherapy in combination with chemotherapy. Receipt of primary (neoadjuvant) chemotherapy is one of the factors associated with prolonged survival when dealing with borderline resectable or locally advanced tumors (other factors are radiotherapy and, when possible, resection) [8$10]$, and it is part of the interventional protocol applied in many such cases. It may also be advantageous in the case of resectable tumors [8, 11-13]. Current therapeutical opportunities are the focus of next section.

\section{Risk factors}

Risk factors for PC have been extensively studied over the last few years [1, 14-17]. Age is considered the most critical determinant, as most patients are diagnosed at age $>50$, with a particularly higher incidence between 70 and 80 . Tobacco smoking is a preventable risk of PC. Indeed, smokers have a two- to three-fold higher risk of developing PC than non-smokers and a favourable effect of discontinuing smoking has been assessed. Other preventable factors are obesity [18], low vegetables and fruit intake and high intake of red meat and saturated fat [19], and low physical activity. An association with heavy alcohol consumption has also been proposed, but it seems that the relationship is due to the risk of chronic pancreatitis associated with excessive alcohol intake. Chronic pancreatitis is a risk factor [20]. Diabetes mellitus is both a risk factor (approximately doubling the risk) [21] and a consequence [22] of early-stage pancreatic cancer. Increased transforming growth factor $\beta$ (TGF $\beta$ ) signalling as cancer progresses determines apoptosis of $\beta$ cells.

A family history of pancreatic cancer accounts for $10 \%$ of patients [17]. Several genomic regions associated with higher risk of developing PC have been identified [23-25] and used to generate a polygenic risk score for PC risk prediction [26], a potentially useful tool since late diagnosis is one of the major causes for this cancer's intractability.

\section{Diversity of pancreatic cancers}

The pancreas has exocrine and endocrine functions, and it is a complex organ. Cells fulfilling a digestive function, accounting for most of the mass, are organized into assemblies, the acini, and are therefore referred to as acinar cells. They secrete enzyme zymogens into ducts formed by columnar epithelial cells. The endocrine cells are also organized in "islets", formed by specialized cells secreting glucagon (alpha cells), insulin (beta cells), pancreatic polypeptide (gamma cells), somatostatin (delta or enterochromaffin cells), ghrelin (epsilon cells), gastrin ( $G$ cells in fetal pancreas) and still other molecules. Consequently, there are a number of histologically and molecularly distinct pancreatic cancers, for an extensive description of which the Reader is referred to $[27,28]$.

Neoplasms of the pancreas are classified as epithelial or non-epithelial according to histological features, and as benign or malignant according to biological behaviour. Epithelial neoplasms can be endocrine or exocrine, the latter being further classified as acinar or ductal. The most common neoplasms of the pancreas are ductal adenocarcinomas, which account for about $90 \%$ of pancreatic cancers, but rare neoplasms also include neuroendocrine tumors, acinar carcinomas, colloid carcinomas, pancreatoblastomas and solid-pseudopapillary neoplasm [29]. The present review refers to Pancreatic Ductal Adenocarcinoma (PDAC) 


\section{Cellular Physiology Cell Physiol Biochem 2021;55:61-90 \\ \begin{tabular}{ll|l} 
and Biochemistry & $\begin{array}{l}\text { DOI: } 10.33594 / 000000326 \\
\text { Published online: } 29 \text { January } 2021\end{array}$ & $\begin{array}{l}\text { C } 2021 \text { The Author(s). Published by } \\
\text { Cell Physiol Biochem Press GmbH\&Co. KG }\end{array}$
\end{tabular} \\ Parrasia et al.: Targeting PDAC}

ignoring the fact that PDAC can itself be further subdivided into various morphologically and genetically distinct subtypes $[15,30]$.

\section{PDAC oncogenes}

Molecular mechanisms underlying pancreatic cancer are very complex. Indeed, it exhibits aberrant autocrine and paracrine signalling, becoming particularly aggressive and invasive. Many molecules such as TGF $\beta$, insulin-like growth factor 1 (IGF1), fibroblast growth factors (FGFs) and epidermal growth factor receptor (EGFR) activate pathways that promote migration and invasion of cancer cells. Moreover, these pathways are activated in parallel with the activation of anti-apoptotic and pro-survival signalling.

PDAC's phenotipical profile is heterogenous and the genetics of pancreatic cancers reveal a who's who of driving oncogenes [31-36]. In fact, on average a pancreatic tumor cell carries some 63 separate mutations [37]. Mutation of KRAS, considered the dominant controller of oncogenic signalling [38, 39], occurs in $90 \%$ of PDAC cases. To be activated, RAS switches from the GDP-bound inactive to the GTP-bound active form, controlling cell proliferation, differentiation and inhibition of apoptosis. The most frequent KRAS point mutations - G12, G13 and Q61 [40] - inhibit its intrinsic GTPase activity, leading to a constitutively active KRAS which can upregulate upstream proteins such as epidermal growth factor receptor (EGFR). Loss of oncosuppressor p53 is analogously common and important [41-43]. Besides p53, the two most often mutated oncosuppressor genes in PDAC are cyclin-dependent kinase inhibitor 2A (CDKN2A/p16/INK4A/CDK4I), a cell cycle regulator [44], and SMAD4/DPC4 (Mothers Against DecaPentaplegic homolog 4/Deleted in Pancreatic Cancer 4), a regulator of gene expression in the transforming growth factor beta (TGF $\beta$ ) pathway [45-47]. The HedgeHog $(\mathrm{HH})[48-50]$ and Wnt/ $\beta$-catenin (WNT) [51,52] pathways are also generally found to be altered.

Aberrant activation (by constitutive phosphorylation at Tyr705) of Signal Transducer and Activator of Transcription-3 (STAT3), e.g. downstream of cytokine signalling or of p53 loss of function, is a major factor in tumor growth, stromal modification, gemcitabine $(2$ ',2'-difluoro 2'deoxycytidine; $\mathrm{dFdC})$ resistance, repression of anti-cancer immune response [53-57]. STAT3 activation increases with tumor progression [58].

\section{Reasons for intractability}

Why is PDAC so difficult to treat? Clinically, it is often nearly asymptomatic up to an advanced stage and symptoms are rather aspecific. These characteristics lead to diagnosis at advanced stages. Moreover, it metastatizes early, it is resistant to pharmacological treatment [59] and difficult to resect because of its location, frequent contact with and/or enclosure of major vessels, and of its tendency to spread which results in poorly defined boundaries. Another characteristic is that pancreatic cancer cells exhibit metabolic abnormalities and insensitivity to growth-inhibitory pathways. For example, TGF $\beta$ promotes tumor progression in pancreatic cancer by a paracrine effect in the tumor microenvironment, inducing cell proliferation and the activation of non-canonical signalling through MAPK [60]. As just hinted in connection with STAT3, PDAC is remarkably good at suppressing the host's anti-cancer immune response. Neoplastic cells appear to produce relatively few neoantigens, and tumor-produced cytokines drive the infiltration of myeloid suppressor cells which block anti-tumor effector T-cell action. This gives a free rein to the tumor and results in the failure of immunotherapy approaches (immune checkpoint blockade) [19, 61-64]. Attempts to remedy this situation are under way $[61,62]$. The cytokines providing this "immune privilege" status to PDAC are generated by the neoplastic cells themselves, as directed by KRAS, but also by cells of the stroma, which may be the most characteristic feature of PDAC.

The stroma

PDAC presents a very pronounced desmoplasia, i.e., malignant cells are surrounded by a complex stroma composed of several types of cells and extracellular matrix, which accounts for more than $80 \%$ of the tumor mass, plays major roles in cancer development and impedes 


\section{Cellular Physiology Cell Physiol Biochem 2021;55:61-90

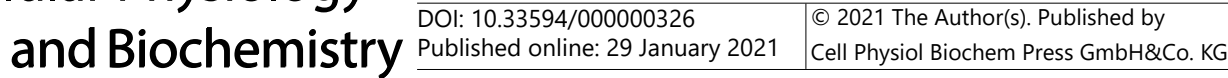

drug delivery [65-67] (Fig. 1). The stroma is itself heterogenous, and three main types have been identified, based on the enrichment in and characteristics of fibroblasts in it [68]. The extracellular matrix contains collagen, fibronectin, laminin, hyaluronic acid, and several other acellular components $[69,70]$. Collagen is the major one, and it increases as the tumor progresses. Hyaluronan is particularly relevant because of its receptor-mediated interactions with cancer cells, modulating adhesion, motility and proliferation [71, 72]. Low molecularweight forms, produced by degradation, are associated with malignant cancer phenotypes. It has therefore become an interventional target $[73,74]$. A major cellular component - along with fibroblasts, macrophages, neutrophils, adipocytes, epithelial cells (venous, arterial, lymphatic), nerve cells etc. - are activated pancreatic stellate cells (PSC), which assume a cancer-associated fibroblast (CAF) functionally heterogenous phenotype and produce the dense extracellular matrix component of stroma [75-80].

Dysregulated activation of PSCs is initiated and fed by inflammatory cytokines [81] and autocrine signalling. Activated PSCs and CAFs (which also have other origins, besides stellate cells) produce various cytokines (e.g. IL-6 $[82,83]$ ) and acetylcholine, thereby crosstalking with cancerous cells and contributing importantly to tumor progression, metastasis, immune evasion and drug resistance [78, 84]. Through these secreted molecules, in particular TGF $\beta[85,86]$, CAFs also interact with immune cells, contributing to the creation of the immunosuppressive tumor microenvironment [76, 79, 86-88]. Immune cells in turn help to maintain the activated state of PSCs/CAFs in a feedback endocrine loop. Fibrogenesis involves several pathways including JAK/STAT, Wnt, SMAD, Hedgehog [78, 79], which are major targets in the efforts to loosen the dense matrix to facilitate access to anti-cancer drugs, as will be discussed in the following sections.

\section{Aims of the review}

Based on the urgent need for the development of effective drugs, the aim of this review is to discuss current and experimental (preclinical) approaches seeking to increase the efficacy of chemotherapy. We focus in particular on the role played by the tumor stroma and on the therapeutic opportunities offered by its targeting. Moreover, we aimed at highlighting the use of peptides as delivery strategy to improve classical chemotherapeutics. It seems to

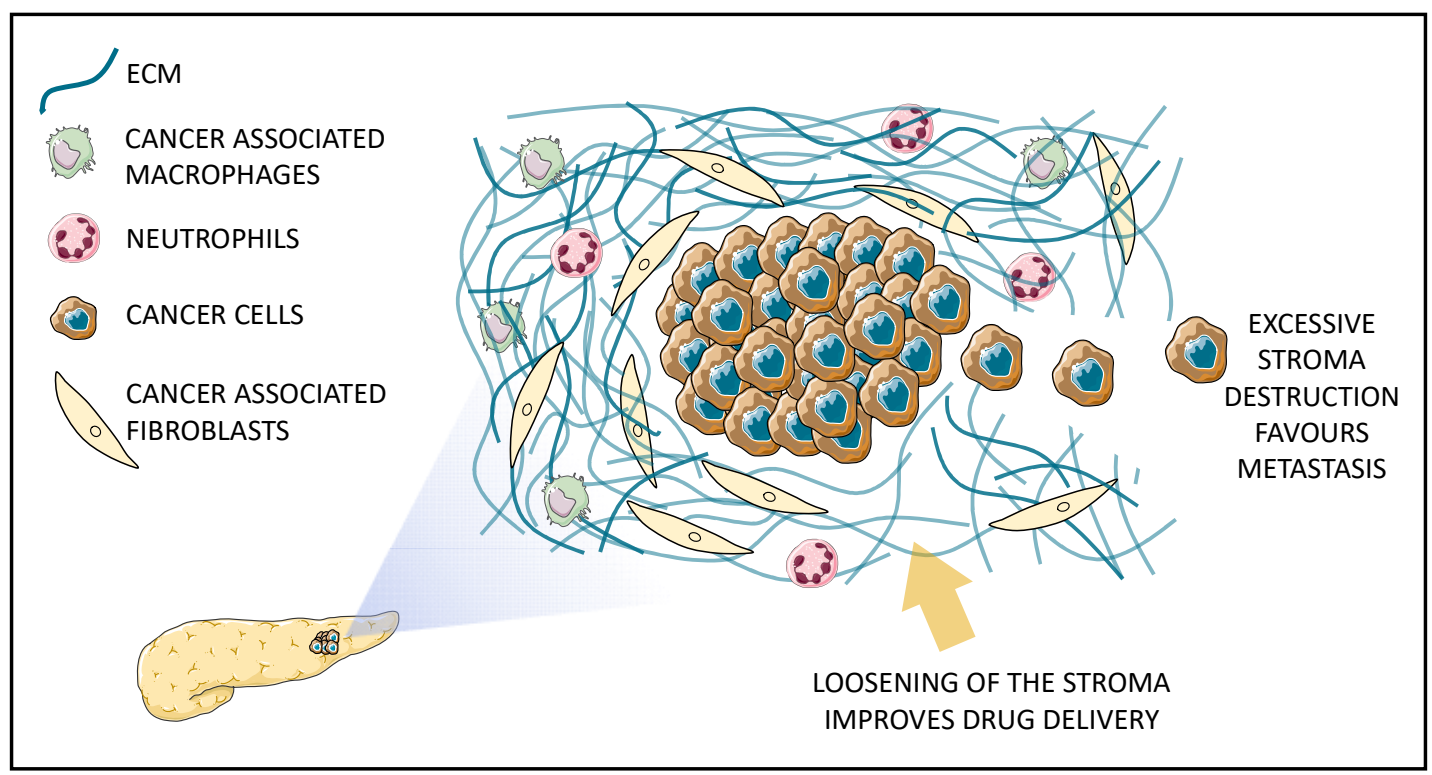

Fig. 1. The presence of an abundant and dense stroma hinders drug delivery to the pancreatic cancer cells, but also helps to contain them within the primary tumor mass. Consequently, pharmacologic strategies loosening the stroma help to improve drug delivery to the tumor mass, but attention must be paid to avoiding its excessive destruction, which on the contrary favours metastasis. 


\section{Cellular Physiology Cell Physiol Biochem 2021;55:61-90 \\ \begin{tabular}{ll|l} 
and Biochemistry & $\begin{array}{l}\text { DOI: 10.33594/000000326 } \\
\text { Published online: } 29 \text { January } 2021\end{array}$ & $\begin{array}{l}\text { C } 2021 \text { The Author(s). Published by } \\
\text { Cell Physiol Biochem Press GmbH\&Co. KG }\end{array}$
\end{tabular} \\ Parrasia et al.: Targeting PDAC}

us that any decisive progress against PDAC will necessarily be accomplished through the development of more effective pharmacological tools and of precision personalized therapy, likely to involve more than one drug. By gathering and making available to specialists but, just as importantly, to the general interested readership, this type of information we hope to contribute to stimulating the transition of new approaches from the lab to clinical trials and eventually to bedside. The number of papers to be considered in such a wide-ranging project is staggering, and we may well have missed some key ones. In many other cases we have not cited relevant work, or even not tackled whole topics (e.g. the role of extracellular vesicles) because of space and time limitations. We apologize to all the researchers whose work is not surveyed as deserved.

\section{Current therapeutical approaches}

The therapeutic treatment of PDAC is a puzzling medical challenge. Progress has been unsatisfactory, and only small increases in the overall survival have been achieved so far. The preferential approach remains tumor surgical resection, when applicable, but even after surgery the median survival is 15-20 months [89]. Unfortunately, the highly invasive nature of the tumor lowers the percentage of patients eligible for surgery. Indeed, at the time of diagnosis, the disease has already spread metastatically in $80 \%$ of cases.

The first drug used for PDAC treatment was 5-fluorouracil (5-FU). In 1997 it was replaced by gemcitabine, that became the cornerstone of PC chemotherapy, with an increased survival benefit of 1.25 months [90].

5-FU, as well as gemcitabine, belongs to the anti-metabolite class. 5-FU is an uracil analogue in which a hydrogen atom at the $\mathrm{C}-5$ position is replaced by a fluorine. To exert its cytotoxic activity, 5-FU is activated by ribosylation and phosphorylation by three different pathways. The final active metabolites responsible for the anti-neoplastic action are 5 -fluorouridine di- and tri-phosphate (FUTP) (which are incorporated into RNA, interfering with RNA function), 5-fluoro-2'-deoxyuridine di- and tri-phosphate (FdUTP) (which instead are incorporated into DNA, leading to DNA damage and cell death), and the monophosphate FdUMP (which inhibits thymidylate synthase). The action on thymidylate synthase leads to the accumulation of dUTP and depletion of deoxythymidine triphosphate. Collectively, these effects impact on DNA synthesis and repair, culminating in cell death [91, 92]. The pharmacokinetics of 5-FU are not advantageous for its anti-neoplastic activity, since some $80 \%$ of the dose is inactivated in the liver by dihydropyrimidine dehydrogenase [93].

Gemcitabine is an anti-metabolite fluoride analogue of deoxycytidine. It is phosphorylated to mono-phosphate by deoxycytidine kinases and then by other kinases, leading to the diand tri-phosphates. Its anti-tumor effect is promoted by multiple mechanisms of action. Gemcitabine di-phosphate inhibits ribonucleotide reductase, dramatically reducing the levels of deoxyribonucleoside triphosphates, needed for DNA synthesis. Gemcitabine triphosphate inhibits DNA polymerases $\alpha$ and $\beta$, leading to the block of DNA synthesis and repair. Gemcitabine tri-phosphate can also be directly incorporated into DNA, leading to the inhibition of DNA synthesis and functions. Cellular uptake of gemcitabine is mediated by ENT1, ENT2 and the concentrative nucleoside transporters 1 and 3 [94, 95]. Gemcitabine is rapidly cleared from plasma via deamination by cytidine deaminase, which converts it to 2',2'-difluoro-2'deoxyuridine [96, 97] and can also be inactivated by dephosphorylation by $5^{\prime}$-nucleotidases [98]. It is not a PC-specific drug, and is used also against other cancers including breast, lung etc. It causes the side effects commonly associated with chemotherapy, e.g. nausea and hair loss, neutropenia as well as general myelotoxicity.

Since 1997, the standard therapeutic protocols have still been limited to "classical" chemotherapies, often administered as combined therapy. Several combinations of gemcitabine plus paclitaxel, capecitabine and cisplatinum were tested but failed to show advantages in comparison to gemcitabine monotherapy. FOLFIRINOX, studied for the first time by the ACCORD11/PRODIGE4 study and introduced in 2011, represents a milestone 
in PC chemotherapy. FOLFIRINOX is a multi-agent therapy composed by folinic acid,fluorouracil, irinotecan (topoisomerase inhibitor) and oxaliplatinum (DNA-alkylating agent) [99-102]. Side effects are however severe, and even this cocktail only provides a survival advantage of a few months over gemcitabine monotherapy [99] (Table 1). The clinical landscape has been recently reviewed in detail [89, 101, 103-107].

Targeted therapies and immunotherapy have been successfully exploited against several solid tumors, but unfortunately efforts in this direction against PDAC were even in the best cases only slightly beneficial. There is therefore an urgent need for the development of novel and effective therapies.

An overview of the clinical trials performed over the last 30 years does not show promising progress; most of them consisted in combinations of classical chemotherapeutics, often terminated because of end-point failure (Table 1). However, the number of clinical trials investigating advanced therapies has recently increased. As reported by Katayama and colleagues, 310 out of the 590 trials considered investigated novel drugs, including 163 small molecules and 120 mAbs. The rest of the studies included mixed pharmacological agents, including biologicals. $14 \%$ investigated combinations or novel delivery systems for drugs already used in PC treatment, 8\% tested drugs already used in other cancers and 9\% investigated radiotherapy. A small percentage of trials is focused on gene therapy or cellular therapy [90].

Many clinical trials have focused on the direct targeting of KRAS by inhibitors or on indirect targeting by inhibition of upstream/downstream regulators (see below). However, direct targeting has had little success because of alternative activation of downstream pathways [108-110]. BI-1701963 was the first pan-KRASi blocking the interaction between KRAS and SOS1, thereby leading to the stabilization of the GDP-bound inactive KRAS. It is under investigation in a phase I/II trial in solid tumors, including PDAC [111].

An alternative strategy is the development of compounds able to specifically target a mutated form of KRAS. The identification of the switch-II-pocket in GDP-KRAS ${ }^{\mathrm{G} 12 \mathrm{C}}$ complexes and covalent binders set the bases for selective targeting of KRAS with the G12C mutation. AMG-510, the clinically most advanced KRAS ${ }^{\mathrm{G} 12 \mathrm{C}}$ inhibitor, showed promising results in patients with colorectal cancer or lung adenocarcinoma. Unfortunately, it has been demonstrated that the KRAS ${ }^{\mathrm{G} 12 \mathrm{C}}$ mutation in PDAC occurs in only 1-3\% of cases [111]. Targeted chemotherapy in PDAC thus requires an accurate selection of the patients, based on biomarkers or the identification of mutations.

The only molecule-targeted therapy approved for PDAC uses erlotinib, an EGFR (epidermal growth factor receptor) inhibitor [35]. Unfortunately, first generation EGFR inhibitors, including gefitinib and erlotinib, did not show great efficacy because of resistance mechanisms mediated by the non-EGFR members of the ERBB family. In clinical research, erlotinib was tested in combination with gemcitabine (CONKO-005) but the results of this trial did not warrant its inclusion [112]. Erlotinib was also tested in combination with Nabpaclitaxel (paclitaxel bound in albumin nanoparticles) in a phase Ib trial but was not welltolerated [113].

Table 1. Main negative-outcome clinical trials. DFS = disease free survival; OS = overall survival

\begin{tabular}{|c|c|c|c|c|}
\hline Study code & Intervention & Treatment groups & Outcome & Reference \\
\hline ESPAC-1 & Adjuvant & 5-FU and folinic acid vs observation & OS improvement & {$[276,277]$} \\
\hline CONKO-001 & Adjuvant & Gemcitabine vs observation & OS improvement & {$[278,279]$} \\
\hline \multirow[t]{5}{*}{ ESPAC-3 } & Adjuvant & 5-FU and folinic acid vs gemcitabine & No differences & {$[280]$} \\
\hline & Adjuvant & Erlotinib in addition to gemcitabine vs gemcitabine & No differences & [112] \\
\hline & Adjuvant & Sorafenib in addition to gemcitabine vs gemcitabine & No differences & [281] \\
\hline & Adjuvant & Algenpantucel-L in addition to gemcitabine vs gemcitabine & No differences & [131] \\
\hline & Adjuvant & Uracil/tegafur in addition to gemcitabine vs gemcitabine & No differences & [282] \\
\hline ESPAC-4 & Adjuvant & $\begin{array}{l}\text { Gemcitabine and capecitabine vs gemcitabine } \\
\text { (irrespective of CA 19-9 levels) }\end{array}$ & $\begin{array}{l}\text { OS increase after } 2 \text { years and } \\
\text { no significant benefit in } \\
\text { recurrence-free survival }\end{array}$ & [283] \\
\hline PRODIGE24-CCTG & Adjuvant & mFOLFIRINOX vs gemcitabine & $\begin{array}{l}\text { Median OS higher in } \\
\text { mFOLFIRINOX group }\end{array}$ & [99] \\
\hline APACT & Adjuvant & $\begin{array}{c}\text { Nanoparticle ablumin-bound nab-paclitaxel and gemcitabine } \\
\text { vs gemcitabine }\end{array}$ & $\begin{array}{l}\text { No differences in median } \\
\text { DFS }\end{array}$ & [132] \\
\hline MAESTRO & Adjuvant & TH-302 in addition to gemcitabine & Discontinued & [121] \\
\hline
\end{tabular}


Due to the failure of first-generation EGFR inhibitors, irreversible Tyrosine kinases (TK) inhibitors afatinib and neratinib have been designed to prevent resistance, and afatinib has shown promising results in lung cancer. A clinical study on PDAC patients is ongoing (NCT02451553) [35].

Treatment with the mAb nimotuzumab, a humanized monoclonal antibody that binds EGFR, was evaluated in a phase II trial and showed an improvement of overall survival (OS), in particular in KRAS wild-type patients. On the other hand, cetuximab (a chimeric monoclonal antibody against EGFR), failed, like vandetanib, a VEGFR-2 inhibitor. Taken together, these multiple failures suggest the presence of resistance mechanisms that pancreatic cancer activates to evade EGFR inhibition. One therapeutic possibility is the combination of two or more agents but while this may be effective in animal models, it dramatically failed in the clinic (for example the application of erlotinib plus selumetinib - an inhibitor of MEK1/2 turned out to have modest efficacy $[114,115])$.

KRAS downstream proteins are also attractive targets. One of these is MEK, which is required for tumor viability and proliferation. Again, MEK inhibitors (i.e. selumetinib and trametinib) failed because of the activation of receptor tyrosine kinases (rTKs) [35]. Currently, phase I and II trials are recruiting patients to study the direct inhibition of MEK with binimetinib or of its upstream regulators such as FAK (focal adhesion kinase) with defactinib (trial code: NCT03637491, NCT03727880 respectively, Table 2; see also Table 3).

Another failure is represented by rigosertib, an inhibitor of PI3K and PLK1, that did not improve prognosis. The same was the case for everolimus, an mTOR inhibitor [35].

DNA damage repair is another target for many classical chemotherapeutics. It has been observed that BRCA-deficient cells are able to repair double strand breaks through error-prone pathways, leading to genome instability and oncogenesis. Of note, BRCA germline mutations represent a risk factor for many cancers such as breast, ovarian and

Table 2. Clinical trials currently recruiting patients. DCR = disease control rate; DFS = disease free survival; $\mathrm{PFS}=$ progression free survival; ORR = objective response rate; OS = overall survival

\begin{tabular}{|c|c|c|c|c|}
\hline Type of treatment & Drugs & Phase & Outcome & Source \\
\hline $\begin{array}{l}\text { Neoadjuvant and } \\
\text { adjuvant }\end{array}$ & $\begin{array}{l}\text { Std therapy plus Pembrolizumab } \\
\text { with and without defactinib }\end{array}$ & II & $\begin{array}{l}\text { Pathological complete response; OS; DFS; } \\
\text { drug related toxicity }\end{array}$ & NCT03727880 \\
\hline Metastatic PC & $\begin{array}{l}\text { leucovorin) and alternating cycles } \\
\text { of NAPOLI and mFOLFOX6 vs } \\
\text { gemcitabine/nab-paclitaxel }\end{array}$ & II & PFS; OS; ORR; DCR & NCT03487016 \\
\hline $\begin{array}{l}\text { Hyaluronan High } \\
\text { Metastatic PDAC }\end{array}$ & PEGPH2 0 plus pembrolizumab & II & PFS & NCT03634332 \\
\hline $\begin{array}{l}\text { Metastatic PDAC and } \\
\text { other locally advanced } \\
\text { or metastatic KRAS or } \\
\text { NRAS mutant solid } \\
\text { tumors }\end{array}$ & $\begin{array}{l}\text { Avelumab, binimetinib and } \\
\text { talazoparib in doublet or triplet }\end{array}$ & $\mathrm{Ib} / \mathrm{II}$ & Dose-limiting toxicity; objective response & NCT03637491 \\
\hline PC and metastatic PC & $\begin{array}{l}\text { Irreversible electroporation plus } \\
\text { nivolumab and Toll-Like } \\
\text { Receptor } 9 \text { ligand (CpG) }\end{array}$ & I & $\begin{array}{l}\text { Safety; OS; PFS; local and systemic } \\
\text { immunomodulation }\end{array}$ & NCT04612530 \\
\hline PDAC & $\begin{array}{l}\text { Niraparib plus nivolumab and } \\
\text { niraparib plus ipilimumab }\end{array}$ & $\begin{array}{l}\text { I and II, } \\
\text { respectively }\end{array}$ & PFS & NCT03404960 \\
\hline
\end{tabular}




\section{Cellular Physiology Cell Physiol Biochem 2021;55:61-90 \\ \begin{tabular}{ll|l} 
and Biochemistry & $\begin{array}{l}\text { DOI: } 10.33594 / 000000326 \\
\text { Published online: } 29 \text { January } 2021\end{array}$ & $\begin{array}{l}\text { C } 2021 \text { The Author(s). Published by } \\
\text { Cell Physiol Biochem Press GmbH\&Co. KG }\end{array}$
\end{tabular} \\ Parrasia et al.: Targeting PDAC}

pancreatic cancer. Olaparib, a PARP1/2 inhibitor, turned out to be effective in a phase II trial (POLO trial) but more trials are needed to confirm the efficacy of PARP inhibitors against BRCAmutated PDAC [116, 117]. A phase Ib/II clinical trial Table 3. Mechanism of action of some targeted drugs

\begin{tabular}{lcc}
\hline Drug & Target & Pathway involved \\
\hline Pembrolizumab & PD-1 receptor inhibitor & T cell activity \\
Defactinib & Focal adhesion kinase (FAK) inhibitor & cell spreading and adhesion \\
Nivolumab & PD-1 receptor inhibitor & T cell activity \\
Avelumab & PD-L1 & T cell activity \\
Binimetinib & MEK1 and MEK2 inhibitor & cell proliferation \\
Talazoparib & PARP1 and PARP2 inhibitor & DNA repair \\
Ipilimumab & CTLA-4 inhibitor & T cell activity \\
\hline
\end{tabular}
is recruiting PDAC patients to evaluate the effect of Talazoparib, a PARP $1 / 2$ inhibitor that is currently used in BRCA1/2-mutated breast cancers (trial code NCT03637491, Table 2; see also Table 3).

Inhibition of the Hedgehog pathway is strongly suggested as a therapeutic approach by what has been learned about the pathophysiology of PDAC (see above and below). However, in clinical trials the co-administration of GDC-0449/ vismodegib - a USFDA-approved inhibitor of Smoothened, a key receptor in the Hedgehog signalling cascade - and gemcitabine [118, 119], or of GDC-0449, gemcitabine and nab-paclitaxel [120] (https://clinicaltrials.gov/ct2/ show/NCT01088815) did not provide a sufficient improvement over gemcitabine alone to warrant further consideration. A clinical trial involving GDC-0449, erlotinib and gemcitabine is currently running (ClinicalTrials.gov Identifier: NCT00878163).

The hypoxia-sensitive prodrug TH-302 (see below) has been studied, together with gemcitabine, in clinical trials for - among others - pancreatic tumors [121] (clinical trial NCT01746979 (MAESTRO), NCT022047500; see: clinicaltrials.gov). Unfortunately, the results led to discontinuation of the trials.

Immunotherapy is a strategy that has been investigated for years in various cancers such as melanoma and lung cancer, reaching clinical approval in many cases. No immunotherapy for PDAC has been approved yet because the tumor microenvironment is believed to create an immunosuppressive milieu $[122,123]$. Based on retrospective studies, only the small sub-group of patients harboring microsatellite instability can be treated with immunotherapy [124-127]. Currently, phase I and II clinical trials are recruiting patients to test immunotherapy approved for other cancers, targeting $\mathrm{T}$ cells response. These trials involve mAbs such as pembrolizumab, nivolumab and avelumab (Table 3), which are directed against PD-1 (programmed cell death protein), a negative regulator of T cells. Its inhibition boosts $\mathrm{T}$ cell responses against the tumor $[128,129]$. Another $\mathrm{mAb}$ under investigation is ipilimumab (trial code: NCT03404960, NCT04117087, Table 2; see also Table 3), an inhibitor of the inhibitory signal induced by the immune checkpoint receptor CTLA-4/CD152, leading to an increase in the reactive $\mathrm{T}$ cells against the tumor cells.

The most advanced attempt to combine gemcitabine with the cancer vaccine Algenpantucel-L [130] did not improve overall survival compared with gemcitabine alone [131].

Formulations like nanoparticles, liposomes and micelles represent a promising strategy to improve the selectivity and the efficacy of classic chemotherapeutics (see below). Many such formulations have been investigated in preclinical studies, but only a few reached the clinic. Albumin-bound nanoparticle nab-paclitaxel and gemcitabine have been evaluated in the APACT trial, in comparison with gemcitabine alone; unfortunately, the median diseasefree survival did not differ between the arms [132].

Irinotecan, a topoisomerase I inhibitor, showed initial evidence of activity in PDAC. To improve its half-life, irinotecan was formulated in a nanoliposomal formulation. In a phase II study, nanoliposomal irinotecan emerged with an acceptable toxicity and an encouraging OS in patients previously treated with gemcitabine [133]. In 2016 the NAPOLI-1 trial assessed the efficacy of nanoliposomal irinotecan alone or in combination with 5-FU and folinic acid, in comparison with the therapy with folinic acid and 5-FU. The results of the study were mildly encouraging, since the treatment was tolerable and increased the median overall survival from 4.2 to 6.1 months [134]. 


\section{Cellular Physiology Cell Physiol Biochem 2021;55:61-90 \\ \begin{tabular}{ll|l} 
and Biochemistry & $\begin{array}{l}\text { DOI: 10.33594/000000326 } \\
\text { Published online: } 29 \text { January } 2021\end{array}$ & $\begin{array}{l}\text { C } 2021 \text { The Author(s). Published by } \\
\text { Cell Physiol Biochem Press GmbH\&Co. KG }\end{array}$
\end{tabular} \\ Parrasia et al.: Targeting PDAC}

As discussed above the stroma developed by PDAC hinders the delivery of drugs. Given the relevance of hyaluronan, a PEGylated recombinant human hyaluronidase (PEGPH20) able to degrade hyaluronan has been developed. A randomized phase II clinical trial showed promising results comparing Nab-paclitaxel/gemcitabine with or without PEGPH20. This trial is progressing as a phase III trial in patients with high hyaluronan levels [135]. PEGPH20 was also tested in combination with a modified FOLFIRINOX protocol but the combination showed an increased toxicity [136] and a trial in combination with pembrolizumab is recruiting patients (trial code: NCT03634332, Table 2).

These (and other analogous) studies involving the relatively straightforward administration of one or more drugs may be considered to fall within the boundaries of a "mainstream" pharmacological approach. The need for more aggressive strategies has led to an intense effort to more directly target PDAC, and specifically the stromal component, with precisely targeted molecules/preparations/nanovehicles. In several cases, multiple strategies have been combined to improve performances. These efforts have been based largely on the use of vehicles meant to promote drug delivery (so-called "nanomedicine"). Again, the results have not met expectations, but past disappointments do not necessarily imply future failures. As new drugs are tested $[137,138]$ it is worthwhile to consider examples of promising vehicles.

\section{Targeting the stroma}

As mentioned, drug delivery to pancreatic tumors is hindered by the abundant and dense stroma. The stroma furthermore contributes to "intrinsic" gemcitabine resistance by influencing the expression of genes involved in gemcitabine metabolism and cell death [139] as well as by recruiting M2 macrophages to the tumor microenvironment upon gemcitabine treatment [140]. So the stroma is itself a target [141], although a complex one because of its variegated composition and because it has been found to act also to contain/enclose neoplastic cells and limit their diffusion (metastasis) [65, 142-144] (Fig. 1). We have already mentioned studies [53-55] concluding that STAT3 inhibition caused remodeling of the stroma and improved drug delivery.

Efforts directed against the stroma have employed nab-paclitaxel together with gemcitabine [145-147], capitalizing on the ability of nab-paclitaxel to decrease the levels of cytidine deaminase (Cda) and possibly to bind, via albumin, to SPARC (Secreted protein acidic and rich in cysteine; a marker and chaperone of tumor-associated ECM located on tumoral and stromal cells [148]). Inhibitors of the HH pathway, e.g. Cyclopamine (CPA) [149], NVP-LDE225 [150] or Vismodegib/GDC-0449 [119] have been used together with one or the other of these drugs in an effort to reduce stroma rigidity, improve vascularisation and decrease hypoxia, while still allowing sufficient matrix stiffness to constrain cancerous cells and keep metastases at bay.

In a 2015 study [58] Merchant's group administered AZD1480, an inhibitor of JAK and hence of the JAK/STAT pathway, with or without gemcitabine as well, to mice bearing

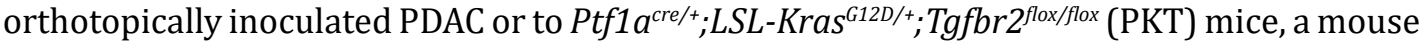
genetic PDAC model [151]. Administration of both drugs together strengthened inhibition of tumor growth, significantly lengthened survival in both models, increased tumor vascularisation, and increased drug delivery to the tumor - as measured by MALDI imaging mass spectrometry. The expression of cytidine deaminase and of SPARC was reduced. Importantly, stromal collagen and hyaluronan were not depleted, but clearly disorganized, with fewer parallel collagen fibers in tumors treated with the two drugs. Thus, the stroma was remodelled but not depleted, avoiding the danger of favouring a more aggressive phenotype and metastases, pointed out by other studies [65, 142-144]. Analogous outcomes were obtained by the same group in the same experimental models by inhibiting instead the Src/EGFR pathway, which is also upstream of STAT3 activation [152]. It ought to be mentioned in this context that a recent study employing SPARC-mutated mice reached the 


\section{Cellular Physiology Cell Physiol Biochem 2021;55:61-90 \\ \begin{tabular}{ll|l} 
and Biochemistry $10.33594 / 000000326$ & Published online: 29 January 2021 & $\begin{array}{l}\text { C } 2021 \text { The Author(s). Published by } \\
\text { Cell Physiol Biochem Press GmbH\&Co. KG }\end{array}$ \\
\hline
\end{tabular} \\ Parrasia et al.: Targeting PDAC}

apparently paradoxical conclusions that the extent of SPARC-dependent collagen deposition did not influence the amount of gemcitabine reaching the tumor and actually had a negative impact on survival [153]. Significant effects on 3D models of PDAC were obtained also with small molecule inhibitors of STAT3 emerging from a 2016 screen, in particular one called PGS3-001 [154]. The list of studies of this type could go on. Of note, several natural compounds, including Urolithin A [155], curcumin [156], xanthohumol [157], owe at least part of their efficacy against PDAC in animal models to their ability to inhibit STAT3.

Pancreatic Stellate Cells (PSCs) have long been in the cross-hairs of pharmacologists' weapons, but so far have largely eluded the projectiles. Treatment with all-trans-retinoic acid (ATRA) currently offers some hope: PSCs maintain deposits of retinoic acid, a precursor of vitamin A, and lose them upon activation. Treatment with ATRA (but not with 9-cis- or 13-cis-retinoic acid) reduced stroma and cancer growth [158]. Its administration along with gemcitabine enhanced anti-tumor efficacy in the genetic mouse KPC model ( $L S L$ $\mathrm{Kras}^{G 12 D /+} ; \mathrm{LSL}-\mathrm{Tr} p 53^{R 172 H /+} ; \mathrm{Pdx}-1-\mathrm{Cre}$ ) [159]. A phase I clinical trial involving administration of ATRA together with gemcitabine and nab-paclitaxel has been recently completed with some success [160].

Another approach may arise from the finding that (pre-)administration of metformin results in weakening of the stromal barrier due to AMPK-mediated reduction of the cytokine TGF $\beta$ production and consequently of the activity of PSCs. This impact then facilitated the delivery of nanoparticles carrying gemcitabine and an acid-sensitive insertion peptide (pHLIP). This resulted in a marked inhibition of tumor (PANC-1 cells) growth in both subcutaneous and orthotopic settings [161].

Zhi-Ren Liu's group has recently developed a tailor-made protein, ProAgio, which binds to Integrin $\alpha_{v} \beta_{3}$-expressing cells, such as the endothelial cells of neovasculature and PSC cells, induces apoptosis and thereby inhibits angiogenesis [162,163]. A PEGylated form of the protein was first administered i.p. to murine models of prostate and breast cancers, in which it proved capable of dramatically decrease the growth of the tumor mass in dosedependent fashion [163]. When tested in 3 in vivo PDAC models (subcutaneous PANC-1 in nude mice; orthotopic KPC 961 cells in C57BL/6J mice; genetic KPC model) with the same administration modalities, PEG-ProAgio also curtailed growth and greatly potentiated the effects of co-administered gemcitabine. The depletion of PSC cells resulted in a more accessible vascular system, release of PSC-trapped gemcitabine, and enhanced drug delivery. Remarkably, this did not result in facilitation of metastases, apparently because IGF-1 levels were reduced. Survival of the mice was drastically improved [162].

Minnelide is a water-soluble prodrug of triptolide, a natural product and anti-cancer drug acting also on PDAC [164]. When tested in KPC mice and in PDX SCID mice it turned out to reduce ECM in stroma and to improve blood vessel functionality, allowing increased drug delivery into the tumor [165]. Unfortunately, this compound may cause CNS toxicity [166]. Several natural phenolic compounds have also shown anti-fibrotic activity, also in pancreatic cancer models [167]. Curcumin, in particular, has been considered as an adjuvant [168, 169].

As mentioned, in PDAC stellate cells crosstalk with cancer cells via HedgeHog signalling, thus promoting tumor development and drug resistance. Sonic HedgeHog ligands act via Patched and Smoothened to upregulate fibroblast cell growth, extracellular matrix deposition and other unfavourable events. An example of work addressing this menage is provided by a study by Wang et al. [170]. The authors combined an inhibitor of Smoothened, DGC-0449/ Vismodegib ( $\mathrm{IC}_{50} 3 \mathrm{nM}$ ), and topoisomerase inhibitor SN38 (the active principle of Irinotecan, which is a prodrug) for simultaneous delivery in nanoparticles. These nanoparticles were essentially formed by a polymeric ester prodrug of SN38 terminating with a PEG chain, useful for solubility and a stealth effect (avoidance of immune response, engulfement by macrophages). Aside from the presence of PEG, no specific strategies were implemented to target tumoral tissue. The NPs showed good loading capacity for DGC-0449, and gradually released SN38 via the action of esterases (elevated in PDAC). Of note, GDC-0449 release was faster than release of SN38, thus the way was so to speak "prepared" for the latter. Nanoparticles containing DGC-0449 showed a somewhat improved outcome with respect 


\section{Cellular Physiology Cell Physiol Biochem 2021;55:61-90 \\ \begin{tabular}{ll|l} 
and Biochemistry & $\begin{array}{l}\text { DOI: } 10.33594 / 000000326 \\
\text { Published online: } 29 \text { January } 2021\end{array}$ & $\begin{array}{l}\text { C } 2021 \text { The Author(s). Published by } \\
\text { Cell Physiol Biochem Press GmbH\&Co. KG }\end{array}$ \\
\hline
\end{tabular} \\ Parrasia et al.: Targeting PDAC}

to those containing SN38 only, with a DGC-0449-dependent increase of SN38 concentration into, and partial suppression of the growth of, an experimental tumor composed of a mixture of PSC cells and BxPC-3 cells injected into the flank of nude mice. The quantifications showed, at the tumor tissue level, an increase in apoptosis and a decrease in collagen and in $\alpha$-Smooth Muscle Actin (a marker of stellate cells). A relevant point is that SN38 and GDC-0449 did not show any synergic effect on cell monocultures (BxPC-3 only). A further point of interest is that GDC-0449 was found to inhibit the upregulation of glucuronosyl transferase and of a drug efflux pump which occurs downstream of the activation of transcription factor GLI-1 (part of the HH pathway; overexpressed in co-cultures of BxPC-3 or PANC-1 cells and PSCs) and acts to decrease the effective concentration of the anticancer drug.

A conceptually very similar approach was used by Zhao and coworkers [149]. In this study the Smoothened inhibitor was Cyclopamine (CPA), rather than GDC-0449, and paclitaxel (PTX) was used instead of SN38 as the anti-tumor drug. These drugs were loaded into micelles made by the combination of copolymers containing PEGylated blocks and negatively charged blocks and copolymers containing again PEG-decorated stretches and positively charged stretches (metacrylate backbone; poly-e-caprolactone capped with succinate; quaternary ammonium cations). The characteristics of the various components were optimized to produce small nanoparticles (approx. $70 \mathrm{~nm}$ diameter), so as to favor penetration into the partially constricted blood vessels of the tumor mass. These NPs however did not carry any specific PDAC-targeting component.

These preparations, and controls, were used in three different mouse models: 1 . an orthotopic model produced by co-injection of human PDAC MIA PaCa-2 cells (transformed to express luciferase for imaging purposes) and Pancreas Stellate Cells (fibroblasts); 2. an orthotopic model produced by implanting into the pancreas of nude mice fragments of human tumor (Patient tumor-Derived Xenograft (PDX) model); 3. a genetic model (KPCLuc), with oncogenic point mutations in both Ras and p53, and crossed so to also express luciferase. These engineered mice spontaneously develop pancreatic tumors at 100-140 days of age. In this model, extensive ablation of the dense stroma that forms has been shown to enhance the invasive phenotype and decrease survival time [142-144]. Of note, in the experiments by Zhao et al. [149] the dose of Cyclopamine (3 injections/week, $5 \mathrm{mg} / \mathrm{Kg}$ ) was only $2-5 \%$ of that used in other studies. The authors wanted to make the point that a moderate interference with desmoplastic stroma can be beneficial, and indeed concluded that this is the case.

In the case of the MIA PaCa-2 model (n. 1) the benefits brought by Cyclopamine were relatively modest. There was a reduction of collagen and $\alpha$-Smooth Muscle Actin (SMA). In the case of the genetic KPC model (n. 3) the Kaplan-Meier survival curves showed drastic improvement in comparison with gemcitabine and Abraxane - which is paclitaxel bound in albumin nanoparticles, i.e., nab-paclitaxel. Importantly, histological analysis showed that the mice treated with M-CPA/PTX had extensive necrosis of the tumor, a lower proportion of poorly differentiated tumor tissue, and conversely a higher proportion of what would be considered a benign form. Another result was that m-CPA/PTX enhanced angiogenesis and reduced Hedgehog and hypoxia signalling, as assessed by qPCR of downstream genes, with however little impact on the collagen matrix.

As for the PDX model (n.2), which incorporated typical PDAC heterogeneity, treatment also antagonized, on average, tumor growth. It also markedly increased the signal given by CD31, a marker of vessel endothelial cells (platelet adhesion factor), while at the same time not depleting $\alpha$-Smooth Muscle Actin (SMA) (marker of PSCs) and collagen (as stained by a specific dye).

In a recent development, Kowolik and coworkers [171] showed that NT1721 - an epidithiodiketopiperazine and a fungal metabolite with anti-cancer properties [172] antagonized Hedgehog signalling by downregulating the GLI1/2 transcription factor. The compound was cytotoxic for pancreatic cancer cell lines, with $\mathrm{IC}_{50}$ values in the sub- $\mu \mathrm{M}$ range, i.e., about one order of magnitude lower than more popular Hedgehog inhibitors such as Vismodegib/GDC-0449 or Erismodegib/Sonidegib/LDE225. In orthotopic mouse models 


\section{Cellular Physiology Cell Physiol Biochem 2021;55:61-90 \\ \begin{tabular}{ll|l} 
and Biochemistry & $\begin{array}{l}\text { DOI: 10.33594/000000326 } \\
\text { Published online: } 29 \text { January } 2021\end{array}$ & $\begin{array}{l}\text { C } 2021 \text { The Author(s). Published by } \\
\text { Cell Physiol Biochem Press GmbH\&Co. KG }\end{array}$
\end{tabular} \\ Parrasia et al.: Targeting PDAC}

carrying luciferase-expressing Panc-1 or Capan-1 cells, oral administration of the compound ( $30 \mathrm{mg} / \mathrm{Kg}$-day, 3 consecutive days per week) decreased tumor growth and liver metastasis and significantly increased survival times in comparison with gemcitabine (i.p., $100 \mathrm{mg} / \mathrm{Kg}$ day, on two non-consecutive days per week).

\section{Targeting hypoxia}

A general characteristic of solid tumors is that they are at least in part hypoxic. As mentioned, this is particularly true of PDAC. Extensive fibrosis is associated with problematic vascularisation, with poorly accessible or blocked microvessels, often with damaged/ collapsed walls, and an uneven blood supply to the tumor mass [173]. This is not just the consequence of mechanical interactions, since stromal cellular components also modulate angiogenesis via paracrine signalling [174]. The consequent hypoxia contributes to the aggressive character of this cancer, in part via a positive feedback on PSC activation [175]. PDAC cell lines grow well in $0.1 \% \mathrm{O}_{2}$, and mitochondria adapted to this situation using respiratory chain supercomplexes [176]. As mentioned, defective vascularisation furthermore strongly contributes to the difficulty in drug delivery to the cancerous tissue (extrinsic resistance to, e.g., gemcitabine). Vascularization may therefore be a target for interventions aiming at its normalization, to actually reduce hypoxia and improve drug delivery. On the other hand an anti-angiogenic approach is also justified, since its goal is to block cancer growth by denying delivery of oxygen and nutrients. A detailed review of these efforts has been published recently [173].

This characteristic hypoxia may be exploited to specifically target drugs to the tumor mass, using hypoxia-sensitive prodrugs, i.e. prodrugs which will release the active principle only in near-anoxia. This approach has been conceived some 40 years ago [177], and a number of such constructs have been realized [178-182]. The mechanism of activation generally involves oxygen-reversible one- or two-electron reduction of the prodrug by cellular oxidoreductases, in particular cytochrome P450 [183]. A one-electron reduction often forms a radical anion which normally is reoxidized by oxygen before it can decompose releasing the active component. At low $\mathrm{O}_{2}$ levels, reoxidation is slow and the prodrug radical anion falls apart delivering the drug.

Possibly the most popular of these prodrugs is 1-methyl-2-nitroimidazole-based evofosfamide (TH-302). The active principle of evofosfamide, bromo-isophosphoramide, is toxic because it cross-links DNA strands. The prodrug has been investigated, together with gemcitabine, in preclinical studies on PDAC animal models. Jessica Sun and colleagues tested TH-302 in murine models of 11 different human cancers, including 3 PDAC ones (Hs766t, BxPC-3 and SU.86.86 cells). Comparisons were made between groups of animals breathing $21 \%, 10 \%$ or $95 \%$ oxygen, and drug efficacy was found to be inversely related to $\mathrm{O}_{2}$ concentration [184]. Sun and colleagues furthermore found that administration of TH302 along with gemcitabine and nab-paclitaxel reduced pancreatic tumor cell proliferation, stroma density and intratumoral hypoxia, but had significant side effects [185]. Evofosfamide synergized with radiation therapy in a murine model of human PDAC [186]. Gillies' and Krishna's groups reported that the co-administration of pyruvate and TH-302 resulted in an increased efficacy of the drug due to a pyruvate-elicited increase in mitochondrial oxygen consumption, further reduction of tumor oxygenation, and consequent increase of the efficacy of the hypoxia-sensitive prodrug $[187,188]$. Kishimoto and colleagues observed that evofosfamide was lethal for the hypoxic regions of PDAC, and at the same time improved oxygenation of the other regions of the tumor, probably because of a reduced oxygen demand [189].

In an interesting development, Kulkarni and associates [190, 191] have prepared hypoxia-responsive "polymersomes" comprising an azobenzene hypoxia-sensitive moiety linking PLA and PEG chains and the cyclic iRGD peptide (see below) conjugated to PEGPLA. While the iRGD peptide delivers better tissue penetration, azobenzene undergoes 


\section{Cellular Physiology Cell Physiol Biochem 2021;55:61-90 \\ \begin{tabular}{ll|l} 
and Biochemistry $\begin{array}{l}\text { DOI: } 10.33594 / 000000326 \\
\text { Published online: } 29 \text { January } 2021\end{array}$ & $\begin{array}{l}\text { C } 2021 \text { The Author(s). Published by } \\
\text { Cell Physiol Biochem Press GmbH\&Co. KG }\end{array}$ \\
\hline
\end{tabular} \\ Parrasia et al.: Targeting PDAC}

reduction under hypoxic conditions, which results in disruption of the polymer structure and liberation of any drug previously loaded into the particle. The polymersomes were loaded with gemcitabine and tested against monolayers and 3D spheroids of BxPC-3 pancreatic cancer cells under normoxia or hypoxia. Analogous polymersomes lacking the hypoxiasensitive link served as control. While hypoxia did function as a GEM-releasing stimulus, the effectiveness of the polymersomes was similar to that of free gemcitabine. In mice carrying the tumor subcutaneously, tail vein injection of polymersomes loaded with a fluorescent dye resulted in dye accumulation in the tumor. This was not observed if the polymersomes did not incorporate the azobenzene linkage. The same strategy has very recently been used by the same group to build a hypoxia-sensitive vector against estrogen receptor-positive breast cancer cells [192]. In a variant, a disulfide bridge has been used instead of the azobenzene linker as a redox sensor. The polymersomes, loaded with gemcitabine plus doxorubicin or with STAT3 inhibitor BBI608 (a.k.a. napabucasin), were decorated with acridine orange, with the iRGD peptide or with dexamethasone to target the glutathione-rich nucleus of prostate and pancreas cancer stem cells in culture and microtumors [193-195]. Alternatively, folate was exposed on the surface and gemcitabine plus doxorubicin constituted the cargo [196]. In another paper the group used a "protected" nuclear localization signal peptide to be unmasked by a proteolytic cut by matrix metalloproteinase MMP-7, expressed in pancreatic tumors. The redox-sensitive polymersomes were loaded with doxorubicin and curcumin, and were tested on cultured cells and 3D spheroids of pancreatic cancer cells [197]. To our knowledge this type of approach has not yet been tested in an orthotopic PDAC model. A shortcoming may be a significant release of some of the possible cargo drugs also under normoxic conditions.

Very recently, Xin and coworkers [198] incorporated the idea in a multifunctional redox(i.e., glutathione-) sensitive nanoplatform in which GEM was linked to a polymeric construct via a disulfide bond. miRNA519 was furthermore complexed into the micelles, which were also decorated with the peptide GE11 (YHWYGYTPQNVI) targeting EGFR [199, 200], highly expressed by the tumor. miRNA519 binds HIF-1 $\alpha$ mRNA and downregulates HIF- $1 \alpha$ expression. Its levels are reduced in pancreatic cancers, thus allowing overexpression of the transcription factor which accounts - along with other effects - for the development of resistance to gemcitabine due at least in part to upregulation of the drug resistance "pump" ABCG2 [201,202]. This complex system was tested in an immunodeficient mouse orthotopic model employing MIA PaCa-2 cells made gemcitabine (GEM)-resistant by prolonged selection. Administration i.v. resulted in evidence of a synergic effect of GEM and miRNA519 (with respect to NPs containing only one or the other principle), and the presence of GE11 increased effectiveness. This approach might well be used with other opportune miRNAs regulating aspects of PDAC pathophysiology, for example miRNA-205, already studied by the same group [203].

The idea of hypoxia-sensitive prodrugs (and drugs) is obviously clever, but its clinical success has so far been limited. Selectivity is often low and side effects relevant. Hypoxic cells generally reside in a poorly accessible "pharmacological sanctuary". Reduction can be catalyzed by various oxidoreductases, which may differ depending on the prodrug moiety, and may or may not be highly expressed in the target cells. Levels of hypoxia and topological distribution of hypoxic regions may differ from case to case. The same can be said for sensitivity to the active drug (tumor heterogeneity). Perhaps most important, this approach is expected to be useful only if hypoxic cells are limiting therapeutic progress. It may be that their loss (if it takes place) has little consequence on tumor growth or aggressiveness. To overcome this, the liberated active principle ought to be able to diffuse out of the hypoxic zone attacking also the cells receiving more oxygen. Furthermore, some of the prodrugs tested are readily metabolized or have extravasation problems. These difficulties, discussed e.g. in [178], largely account for the limited success this approach has had so far. Nonetheless, it may be worthwhile to keep working along this line, possibly combining this strategy with others, such as radiation therapy [204]. 


\section{Cellular Physiology Cell Physiol Biochem 2021;55:61-90 \\ \begin{tabular}{ll|l} 
and Biochemistry & $\begin{array}{l}\text { DOI: } 10.33594 / 000000326 \\
\text { Published online: } 29 \text { January } 2021\end{array}$ & $\begin{array}{l}\text { C } 2021 \text { The Author(s). Published by } \\
\text { Cell Physiol Biochem Press GmbH\&Co. KG }\end{array}$ \\
\hline
\end{tabular} \\ Parrasia et al.: Targeting PDAC}

\section{Peptides as delivery agents}

A major conceptual advance in pharmacology has been the development of peptides as target-recognition tools. Given the versatility provided by the extremely large number of possible combinations of natural and unnatural aminoacids, they can function as a junior league version of antibodies. Peptides recognizing just about any desired target/epitope can be obtained by selection from degenerate libraries using the by now well-established methods of phage display $[205,206]$. They can then serve to selectively deliver "cargoes", either conjugated molecules or nanovehicles. In the latter case their avidity - often relatively low for a single peptide - can be increased by the presence of multiple neighboring copies. Peptides targeting tumor vasculature can be very useful in oncology, since tumor vasculature expresses a number of specific markers related to angiogenesis and can therefore be attacked while sparing normal blood vessels [207-210]. One example of these epitopes are integrins $\alpha_{v} \beta_{3}$ and $\alpha_{v} \beta_{5}$, targeted by peptides containing the cell-adhesion RGD motif [211]. A variant is the cyclic iRGD peptide (CRGDKGPDC and variants). This binds as expected to integrins, and is subsequently cut by proteases to produce the CRGDK sequence (a "C-end Rule/CendR" motif: $(\mathrm{R} / \mathrm{K}) \mathrm{XX}(\mathrm{R} / \mathrm{K})$ ), which binds neuropilin-1 (NRP-1), extravasates, and penetrates the tumor (i.e., it is a "tumor penetrating peptide") [212-214] (for possible complications associated with the use of iRGD see [215]). Peptides with the CendR motif not only target the endothelia of tumoral vases, but also act as cell-penetrating peptides, undergoing transcytosis and allowing, in principle at least, the delivery of conjugated drugs, or of drugs co-transported in a nanovehicle, to the tumor parenchyma. Inverso-isomer peptides also work. Neuropilins are multi-functional co-receptors, involved in a variety of signalling pathways, and an anticancer target of their own [216, 217], with much relevance also for PDAC [218, 219]. Various peptides targeting NRP-1 have been tested against cancers other than PDAC [220, 221]. It may be worthwhile to verify their performance in PDAC models as well. Incidentally, NRP-1 is also a host factor in SARS-Covid19 infection [222]. CD13 (Aminopeptidase N; a membrane metalloprotease which promotes angiogenesis, tumor growth and metastasis), is targeted instead by peptides containing the fibrinogen NGR motif [209, 211, 223].

Peptides homing selectively to these markers can for example be discovered by screening phage display libraries in vivo, in animals bearing the tumor (e.g. [211]). While some peptides specifically recognizing epitopes present in only one or a few tumors have been identified [209], most bind to the neo-vasculature of multiple cancers, due to the common expression of angiogenic factors. This of course does not constitute a clinically relevant problem.

These peptides can be conjugated to "standard" drugs and proteins. Thus, for example, daunomycin [224], docetaxel [225], the death-inducing peptide KLAKLAK [226], TNF [227229] have been conjugated to NGR peptides. The Clincaltrials.gov site lists (November, 2020) 18 clinical trials employing NGR-TNF constructs against cancers (none however against PDAC).

Peptides are perhaps more often used to target nanovehicles to tumor tissue. For example, NGR peptides have been used to decorate doxorubicin-loaded liposomes [230] or ultrasound-sensitive "nanobubbles" [231], addressing them to tumor xenografts. For example, Zhu et al. [232] used the sequence CKAAKN, which recognizes the Frizzled receptor of the WNT pathway (see above and below) to functionalize polymeric magnetic nanoparticles which selectively accumulated into pancreatic cancer cells (vs. non-cancerous cells) in vitro. In a recent study by Dókus et al. [233] the conjugated drug was daunomycin, connected to the peptide via an aminooxyacetyl moiety, which allows the release of an active metabolite in lysosomes. Various constructs were tested in SCID mice carrying PANC-1 subcutaneous tumors. The best results were obtained using the sequence SKAAKN (rather than CKAAKN), and linking two molecules of daunomycin to the targeting peptide via the introduction of another lysine. Two copies of the Cathepsin B-sensitive sequence GFLG were also introduced, so that the final molecule (n. 4 in the paper) was (Dau)-GFLG-K(Dau)-GFLGSKAAKN [233]. However, only a relatively modest decrease of tumor growth was obtained. 


\section{Cellular Physiology Cell Physiol Biochem 2021;55:61-90 \\ \begin{tabular}{ll|l} 
and Biochemistry & $\begin{array}{l}\text { DOI: } 10.33594 / 000000326 \\
\text { Published online: } 29 \text { January } 2021\end{array}$ & $\begin{array}{l}\text { C } 2021 \text { The Author(s). Published by } \\
\text { Cell Physiol Biochem Press GmbH\&Co. KG }\end{array}$
\end{tabular} \\ Parrasia et al.: Targeting PDAC}

\section{“Improving" gemcitabine}

Since gemcitabine has been the keystone of PDAC chemotherapeutics, much research has gone into improving its shortcomings, namely a rapid metabolization/elimination, high hydrophilicity hampering cellular uptake, facile export by MDR pumps, propensity to elicit resistance. The molecule has been therefore modified in various ways and packaged in assorted nanocarriers in attempts to improve its efficacy.

\section{Gemcitabine (GEM) lipid derivatives}

In this line of investigation hydrophilic gemcitabine is modified by coupling to a hydrophobic tail in prodrug fashion, to increase bioavailability and delivery to the tumor. An example of this approach is that of squalenoyl gemcitabine (SqGEM) [234, 235]. In this compound, the 4-amino group of gemcitabine is linked to squalenic acid in an amide bond. The squalene moiety thus forms a lipidic "tail" leading to self-assembly into micelles or nanoparticles. This construct safeguards gemcitabine from metabolism, inserts into cellular membranes, and turned out to be somewhat more effective than gemcitabine itself in pancreatic cancer models (including orthotopic ones) [236]. The micelles formed by SqGEM have been used as carriers of other chemotherapeutics as well [237, 238].

Similar constructs incorporating other lipidic "tails" produced nanoparticles and similar outcomes $[239,240]$. Other polyisoprenoyl gemcitabine conjugates were tested by P. Couvreur and associates [241]. Stearoyl gemcitabine was first synthesized and tested by L. Cattel and coworkers [242, 243] and then developed by the group led by Zhengrong Cui [244-246]. Cui's group also produced and tested on Panc-1 tumors, both subcutaneous and orthotopically implanted, with good results, a variant with a polyunsaturated "tail", 4-(N)-docosahexaenoyl gemcitabine (4-(N)-docosahexaenoyl $2^{\prime}, 2^{\prime}$-difluorodeoxycytidine; DHA-dFdC) [247, 248]. These drugs were usually administered i.v. (e.g. [247]), but may also work after oral administration (e.g. [249]). One question that remains open in this field of investigation is the pathway of cell entry and GEM release utilized by these constructs. SqGEM does find its way to cell membranes, in particular the endoplasmic reticulum, and delivers GEM to the cytoplasm [250]. At high concentrations, it can induce lysis of erythrocytes [251]. Sobot and colleagues have presented evidence for an interaction of SqGEM with endogenous lipoprotein particles - especially the cholesterol-rich ones (LDL) - in vivo, and suggest the involvement of LDLR and that this may represent a generally useful delivery path for squanoylated compounds to LDLR-high cancers [252]. Interestingly, LDLR is highly expressed in pancreatic cancers, and is considered a metabolic driver of the disease [253, 254].

\section{Gemcitabine-peptide conjugates}

Gemcitabine has been conjugated to the integrin-targeting peptide RGDV mentioned above [255]. The construct has been reported to form nanoparticles in water, to constitute a marked improvement over GEM itself in terms of in vivo systemic half-life, anti-tumor efficacy (subcutaneous S180 ascite tumor; oral drug administration) and development of drug resistance, and to have negligible toxicity. The RGD motif led to targeting of the tumor mass and release of GEM in it. It was also tested with satisfying results in a model of lung cancer metastasis [256]. Rather than using RGD, Cochran's group has used an engineered cystine-knot mini-protein ("knottin") targeting integrin receptors. GEM was linked to the protein in various ways, and the constructs were tested against several cell lines, including the BxPC-3 and PANC-1 pancreatic cancer lines. A construct employing a valyl-alanyl-para-aminobenzyloxy linker was selected. Effectiveness was much increased in comparison with GEM itself, a finding attributed to a better internalization [257]. GEM has furthermore been coupled to two well-known cell-penetrating peptides: penetratin/ antennapedia (RQIKIWFQNRRMKWKK) and pVEC (from vascular endothelial cadherin; LLIILRRRIRKQAHAHSK) [258], or to CPPs formed by various combinations of arginine and tryptophan [259]. These constructs were evaluated on cell lines of gastric, colorectal and 


\section{Cellular Physiology Cell Physiol Biochem 2021;55:61-90 \\ \begin{tabular}{ll|l} 
and Biochemistry & $\begin{array}{l}\text { DOI: } 10.33594 / 000000326 \\
\text { Published online: } 29 \text { January } 2021\end{array}$ & $\begin{array}{l}\text { C } 2021 \text { The Author(s). Published by } \\
\text { Cell Physiol Biochem Press GmbH\&Co. KG }\end{array}$
\end{tabular} \\ Parrasia et al.: Targeting PDAC}

lung carcinoma, and showed an increase of anti-proliferative activity, although their in vivo efficacy remains to be established.

In another approach, GEM was linked in various ways to a decapeptide targeting the gonadotropin releasing hormone receptor (GnRHR) and the constructs were tested in vitro with satisfactory results against two prostate and two breast cancer cell lines [260]. Gaokar et al. [261] linked it instead to peptides containing motifs found in the SPARC protein (see above) and tested the constructs in a melanoma model. We are not aware of any tests of any of these constructs on in vivo PDAC models.

Gemcitabine has been linked to albumin via a cathepsin B-cleavable peptide (GFLG) [262]. In a PxPC-3 murine pancreatic tumor model, drug metabolism (deamination) and elimination was slowed down, and the concentration of the active form (the triphosphate) in the tumor mass increased (administration: i.v. tail vein). GEM has also been incorporated into nab-albumin nanoparticles after modification by myristoylation. The nanoparticles were furthermore decorated with cyclised RGD, and had a marked effect on BxPC-3 cells in culture [263]. Already in 2012 Shunrong Ji and coworkers had developed albumin nanoparticles modified with the RGD peptide which could effectively deliver cargo gemcitabine to BxPC-3 cells both in vitro and in vivo [264].

One-aminoacid prodrugs of GEM have also been produced with the goal of improving its stability and bioavailability. Amidon's group synthesized various such derivatives, intending to exploit peptide transport systems. Two compounds, the 5'-L-valyl and 5'-L-isoleucyl monoester prodrugs, showed increased uptake into HeLa cells expressing the hPEPT1 carrier (a.k.a. solute carrier family 15 member 1 (SLC15A1)) [265]. The prodrug stability profile was improved using D-aminoacids [266]. Assays on Panc-1 and Capan-2 PDAC cell lines indicated an increase of antiproliferation activity in comparison with GEM itself [267]. However, in vivo pharmacokinetics of one of the most promising derivatives, 5'-L-valyl-gemcitabine, after i.v. and oral administration, revealed a rapid elimination and low oral bioavailability, with an overall systemic exposure to GEM on a par with that obtained with GEM itself [268].

Gold nanoparticles have been used to deliver grafted gemcitabine to PDAC thanks to decoration with peptides targeting PDAC marker plectin-1 (tested with good results in a PANC-1 orthotopic xenograft model) [269, 270].

\section{Gemcitabine/lipid/peptide combinations}

Valetti and coworkers [271] obtained interesting results by taking advantage of the two approaches mentioned above: the use of SqGEM and of a tumor vascular-homing peptide, combined together in the same nanovehicles. In this case, this latter tool was provided by a study by Joyce et al. [272]. These authors used ex vivo and in vivo phage display/biopanning in a transgenic mouse model (Rip-Tag2) of a pancreatic (Langerhans islet cell) carcinoma, investigating different angiogenic stages. They identified several peptides most of which specifically homed to the neovasculature of endocrine pancreas tumors and did not bind to normal vasculature nor to the blood vessels of a few other cancers implanted under the skin (including cultured cells derived from an islet tumor). Valetti et al. used a squalenoylated derivative of the peptide with the sequence CKAAKN. The combination of this molecule with SqGEM (1:100 ratio) resulted in the formation of regular nanoparticles with a diameter of about $100 \mathrm{~nm}$. Interestingly, the CKAAKN peptide shares the CKA-K motif with Wnt2, one of the Wnt proteins, and in fact in Surface Plasmon Resonance experiments with a Frizzled receptor (actually a Frizzled-related protein with high similarity to FZD-5) the nanoparticles functionalized with the peptide produced a strong signal. The peptide itself produced instead only a weak signal. This is attributable to the presence in the nanoparticles of multiple copies, allowing an increase in the avidity of binding, which for single peptides is generally low. This putative involvement of a receptor of the Wnt system may be relevant, since Wnt is one of the signalling pathways activated in pancreatic - and in many other - cancers.

As hoped for, in a genetic, i.e., orthotopic model of pancreatic carcinoma (the Rip-Tag2 mouse, the same used by Joyce et al. for the discovery of the peptide sequence) the presence 


\section{Cellular Physiology Cell Physiol Biochem 2021;55:61-90 \\ \begin{tabular}{ll|l} 
and Biochemistry & $\begin{array}{l}\text { DOI: } 10.33594 / 000000326 \\
\text { Published online: } 29 \text { January } 2021\end{array}$ & $\begin{array}{l}\text { C } 2021 \text { The Author(s). Published by } \\
\text { Cell Physiol Biochem Press GmbH\&Co. KG }\end{array}$
\end{tabular} \\ Parrasia et al.: Targeting PDAC}

of the squalenoylated peptide construct led to an increased localization of nanoparticles to the blood vessel epithelia. What is most important, administration of this preparation resulted in a decrease of tumor volume, an increase in apoptosis, and a marked reduction of histological staining for a blood vessel epithelial marker (i.e., a reduction of blood vessels), in comparison with the administration of gemcitabine itself or of the nanoparticles without homing peptide. On the contrary, pericyte coverage of the remaining blood vessels increased, suggesting an overall "normalization" of the tumor vasculature, hopefully permitting better oxygenation and drug access.

The study leaves some questions open. One, alluded to above, is that of the path taken by the NPs to enter cells. The CKAAKN peptide does not seem to have the properties of a cellpenetrating peptide, and it was used at a relatively low density in these nanoparticles. It may be that gemcitabine is released outside or at the membrane of the cells, and is then taken up via the carrier it normally uses, i.e. ENT-1. SqGEM does find its way to the cell membrane, and, at high concentrations, can induce lysis of erythrocytes [251]. Thus, the nanoparticleforming prodrug, rather than the drug itself, might conceivably be the cytotoxic agent. It is in any case worth emphasizing the homing properties conferred by the CKAAKN peptide, which may find application in the delivery of other nanoparticles/cargos, and has in fact already been used in the context of PDAC targeting.

An approach similar to that of Valetti et al. was adopted recently by Liming $\mathrm{Wu}$ and coworkers [273]. In this case GEM was modified by PUFAylation, i.e. the attachment at the 4-(N) position, via an amide bond, of a poly-unsaturated acyl group. This resulted in the formation of nanoparticles which were further elaborated by PEGylation and by the inclusion of a peptide (amino acid sequence: H2N-KTLLPTP-GGGC-COOH; KTLLPTP is the key sequence) targeting plectin-1, a recognized marker of PDAC [274, 275]. I.v. administration of the NPs resulted in a drastic decrease of tumor growth in murine subcutaneous PDAC models, including one in which the tumors implanted in immunodeficient mice consisted of fragments from an explanted human tumor mass. Growth inhibition was especially dramatic with the peptide-decorated nanoparticles. Two out of eight mice treated in this way were completely cured at the end of the 27-day administration period [273]. Side effects were negligible. However, experiments in genetic PDAC models should confirm efficacy of this approach, as in mice with subcutaneously injected PDAC the tumor microenvironment and stroma may substantially differ from that of the tumor growing in the pancreas.

\section{Perspectives}

PDAC is a very stubborn and complex (set of) disease(s). Its stubborness is closely linked to its complexity. Investigators and would-be healers need to be stubborn as well, and since simple solutions of complex problems are rare, the therapeutic approach probably needs to be complex also. In fact, pharmacological strategies are becoming more and more complex. In the clinic, we have moved, when possible, from one drug (gemcitabine) to a combination of four drugs (FOLFIRINOX). Multiple drugs given together are expected to have a cumulative effect. This is especially true if some prepare the grounds "softening" the stroma and others go after the cancerous cells. Stroma softening may also alter the metabolism of the tumor cells, a point worth investigating. In preclinical studies, multi-functionalized nanovehicles are used more and more often. Nanotechnology may well carry the day, one day, by providing for specific delivery to the tumor of different drugs, packaged together in a parcel. Treating the whole body with combination therapy is a low-efficiency approach, and entails the risks of hitting off-targets and causing severe side effects. If however the nanoparticles can efficiently deliver their payload where it's needed, the danger decreases and the chances of success increase. It's a bit like personalized medicine vs. general chemotherapy. What we are looking for is a precision-guided vehicle delivering a deadly cocktail of drugs where needed. Currently we have neither, but progress is being made. One cannot help but look with hope 


\section{Cellular Physiology Cell Physiol Biochem 2021;55:61-90 \\ \begin{tabular}{c|c|c|c|c|} 
DOl: 10.33594/000000326 & O 2021 The Author(s). Published by \\
and Biochemistry Published online: 29 January 2021 & Cell Physiol Biochem Press GmbH\&Co. KG
\end{tabular} \\ Parrasia et al.: Targeting PDAC}

to tests in humans of such innovations as the ProAgio protein or the decorated nanoparticles targeting plectin. Most of all, we need a coordinated program, on a supra-national scale, allowing the simultaneous testing on humans of the most promising devices being developed in preclinical animal models.

\section{Acknowledgements}

The authors thank Prof. Michael Edwards (University of Cincinnati), Prof. Erich Gulbins (University of Duisburg-Essen) and colleagues for useful discussion and collaboration on the topics related to this paper.

The figure was created using images from Servier Medical Art (http://smart.servier.com). Servier Medical Art by Servier is licensed under a Creative Commons Attribution 3.0 Unported License.

\section{Funding}

Authors were supported by a grant from AIRC (IG 2017, Id.20286), by the CNR InterOmics project (GLIOMICS), and by the Italian Ministry of University and Education (PRIN 20174TB8KW_004).

\section{Disclosure Statement}

The authors have no conflicts of interest to declare.

\section{References}

1 Mizrahi JD, Surana R, Valle JW, Shroff RT: Pancreatic cancer. Lancet 2020;395:2008-2020.

2 NIH, Cancer Stat Facts: Pancreatic Cancer. URL: https://seer.cancer.gov/statfacts/html/pancreas.html.

3 Bray F, Ferlay J, Soerjomataram I, Siegel RL, Torre LA, Jemal A: Global cancer statistics 2018: GLOBOCAN estimates of incidence and mortality worldwide for 36 cancers in 185 countries. CA Cancer J Clin 2018;68:394-424.

4 Siegel RL, Miller KD, Jemal A: Cancer statistics, 2020. CA Cancer J Clin 2020;70:7-30.

5 Saad AM, Turk T, Al-Husseini MJ, Abdel-Rahman 0: Trends in pancreatic adenocarcinoma incidence and mortality in the United States in the last four decades; a SEER-based study. BMC Cancer 2018;18:688.

6 Rahib L, Smith BD, Aizenberg R, Rosenzweig AB, Fleshman JM, Matrisian LM: Projecting cancer incidence and deaths to 2030: the unexpected burden of thyroid, liver, and pancreas cancers in the United States. Cancer Res 2014;74:2913-2921.

7 Chikhladze S, Lederer AK, Kousoulas L, Reinmuth M, Sick O, Fichtner-Feigl S, et al.: Adjuvant chemotherapy after surgery for pancreatic ductal adenocarcinoma: retrospective real-life data. World J Surg Oncol 2019;17:185.

8 Müller PC, Frey MC, Ruzza CM, Nickel F, Jost C, Gwerder C, et al.: Neoadjuvant Chemotherapy in Pancreatic Cancer: An Appraisal of the Current High-Level Evidence. Pharmacology 2020:1-11.

9 Silvestris N, Longo V, Cellini F, Reni M, Bittoni A, Cataldo I, et al.: Neoadjuvant multimodal treatment of pancreatic ductal adenocarcinoma. Crit Rev Oncol Hematol 2016;98:309-324.

10 Maggino L, Malleo G, Marchegiani G, Viviani E, Nessi C, Ciprani D, et al.: Outcomes of Primary Chemotherapy for Borderline Resectable and Locally Advanced Pancreatic Ductal Adenocarcinoma. JAMA Surg 2019;154:932-942.

11 da Costa WL, Jr., Tran Cao HS, Sheetz KH, Gu X, Norton EC, Massarweh NN: Comparative Effectiveness of Neoadjuvant Therapy and Upfront Resection for Patients with Resectable Pancreatic Adenocarcinoma: An Instrumental Variable Analysis. Ann Surg Oncol 2020; DOI: 10.1245/s10434-020-09327-3.

12 Nassour I, Adam MA, Kowalsky S, Al Masri S, Bahary N, Singhi AD, et al.: Neoadjuvant therapy versus upfront surgery for early-stage left-sided pancreatic adenocarcinoma: A propensity-matched analysis from a national cohort of distal pancreatectomies. J Surg Oncol 2021;123:245-251. 


\section{Cellular Physiology Cell Physiol Biochem 2021;55:61-90

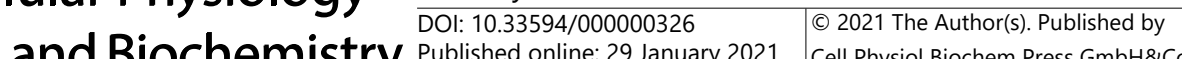 and BIOChemistry Published online: 29 January $2021 \quad$ Cell Physiol Biochem Press GmbH\&Co. KG \\ Parrasia et al.: Targeting PDAC}

13 Sugimoto M, Takahashi N, Farnell MB, Smyrk TC, Truty MJ, Nagorney DM, et al.: Survival benefit of neoadjuvant therapy in patients with non-metastatic pancreatic ductal adenocarcinoma: A propensity matching and intention-to-treat analysis. J Surg Oncol 2019;120:976-984.

14 Principe DR, Rana A: Updated risk factors to inform early pancreatic cancer screening and identify high risk patients. Cancer Lett 2020;485:56-65.

15 Barcellini A, Peloso A, Pugliese L, Vitolo V, Cobianchi L: Locally Advanced Pancreatic Ductal Adenocarcinoma: Challenges and Progress. Onco Targets Ther 2020;13:12705-12720.

16 Lu Y, Gentiluomo M, Lorenzo-Bermejo J, Morelli L, Obazee O, Campa D, et al.: Mendelian randomisation study of the effects of known and putative risk factors on pancreatic cancer. J Med Genet 2020;57:820-828.

17 Aier I, Semwal R, Sharma A, Varadwaj PK: A systematic assessment of statistics, risk factors, and underlying features involved in pancreatic cancer. Cancer Epidemiol 2019;58:104-110.

18 Chung KM, Singh J, Lawres L, Dorans KJ, Garcia C, Burkhardt DB, et al.: Endocrine-Exocrine Signaling Drives Obesity-Associated Pancreatic Ductal Adenocarcinoma. Cell 2020;181:832-847.e818.

19 Padoan A, Plebani M, Basso D: Inflammation and Pancreatic Cancer: Focus on Metabolism, Cytokines, and Immunity. Int J Mol Sci 2019;20:676.

20 Vujasinovic M, Dugic A, Maisonneuve P, Aljic A, Berggren R, Panic N, et al.: Risk of Developing Pancreatic Cancer in Patients with Chronic Pancreatitis. J Clin Med 2020;9:3720.

21 Duvillié B, Kourdoughli R, Druillennec S, Eychène A, Pouponnot C: Interplay Between Diabetes and Pancreatic Ductal Adenocarcinoma and Insulinoma: The Role of Aging, Genetic Factors, and Obesity. Front Endocrinol (Lausanne) 2020;11:563267.

22 Parajuli P, Nguyen TL, Prunier C, Razzaque MS, Xu K, Atfi A: Pancreatic cancer triggers diabetes through TGF- $\beta$-mediated selective depletion of islet $\beta$-cells. Life Sci Alliance 2020;3:e201900573.

23 Gentiluomo M, Canzian F, Nicolini A, Gemignani F, Landi S, Campa D: Germline genetic variability in pancreatic cancer risk and prognosis. Semin Cancer Biol 2020; DOI: 10.1016/j.semcancer.2020.08.003.

24 Yuan F, Hung RJ, Walsh N, Zhang H, Platz EA, Wheeler W, et al.: Genome-Wide Association Study Data Reveal Genetic Susceptibility to Chronic Inflammatory Intestinal Diseases and Pancreatic Ductal Adenocarcinoma Risk. Cancer Res 2020;80:4004-4013.

25 Campa D, Gentiluomo M, Obazee O, Ballerini A, Vodickova L, Hegyi P, et al.: Genome-wide association study identifies an early onset pancreatic cancer risk locus. Int J Cancer 2020;147:2065-2074.

26 Galeotti AA, Gentiluomo M, Rizzato C, Obazee 0, Neoptolemos JP, Pasquali C, et al.: Polygenic and multifactorial scores for pancreatic ductal adenocarcinoma risk prediction. J Med Genet 2020; DOI: 10.1136/jmedgenet-2020-106961.

27 Centeno BA, Dhillon J: Subject Index, in Centeno BA, Dhillon J (eds): Pancreatic Tumors. Monogr Clin Cytol. Basel, Karger, 2020, vol 26, pp 130-134.

28 Pathology Outlines, Pancreas, WHO Classification. URL: http://www.pathologyoutlines.com/topic/ pancreaswho.html.

29 Haeberle L, Esposito I: Pathology of pancreatic cancer. Transl Gastroenterol Hepatol 2019;4:50.

30 Puleo F, Nicolle R, Blum Y, Cros J, Marisa L, Demetter P, et al.: Stratification of Pancreatic Ductal Adenocarcinomas Based on Tumor and Microenvironment Features. Gastroenterology 2018;155:19992013.e1993.

31 Witkiewicz AK, McMillan EA, Balaji U, Baek G, Lin WC, Mansour J, et al.: Whole-exome sequencing of pancreatic cancer defines genetic diversity and therapeutic targets. Nat Commun 2015;6:6744.

32 Wood LD, Hruban RH: Pathology and molecular genetics of pancreatic neoplasms. Cancer J 2012;18:492501.

33 Pelosi E, Castelli G, Testa U: Pancreatic Cancer: Molecular Characterization, Clonal Evolution and Cancer Stem Cells. Biomedicines 2017;5:65.

34 Sun H, Zhang B, Li H: The Roles of Frequently Mutated Genes of Pancreatic Cancer in Regulation of Tumor Microenvironment. Technol Cancer Res Treat 2020;19:1533033820920969.

35 Qian Y, Gong Y, Fan Z, Luo G, Huang Q, Deng S, et al.: Molecular alterations and targeted therapy in pancreatic ductal adenocarcinoma. J Hematol Oncol 2020;13:130.

36 Thompson ED, Roberts NJ, Wood LD, Eshleman JR, Goggins MG, Kern SE, et al.: The genetics of ductal adenocarcinoma of the pancreas in the year 2020: dramatic progress, but far to go. Mod Pathol 2020:33:2544-2563.

37 Jones S, Zhang X, Parsons DW, Lin JC, Leary RJ, Angenendt P, et al.: Core signaling pathways in human pancreatic cancers revealed by global genomic analyses. Science 2008;321:1801-1806. 


\section{Cellular Physiology Cell Physiol Biochem 2021;55:61-90 \begin{tabular}{l|l|l} 
DOI: 10.33594/000000326 & (c) 2021 The Author(s). Published by
\end{tabular} and Biochemistry Published online: 29 January $2021 \quad$ Cell Physiol Biochem Press GmbH\&Co. KG \\ Parrasia et al.: Targeting PDAC}

38 Singh K, Pruski M, Bland R, Younes M, Guha S, Thosani N, et al.: Kras mutation rate precisely orchestrates ductal derived pancreatic intraepithelial neoplasia and pancreatic cancer. Lab Invest 2020; DOI:10.1038/ s41374-020-00490-5.

39 Liu J, Ji S, Liang C, Qin Y, Jin K, Liang D, et al.: Critical role of oncogenic KRAS in pancreatic cancer (Review). Mol Med Rep 2016;13:4943-4949.

40 Hobbs GA, Der CJ, Rossman KL: RAS isoforms and mutations in cancer at a glance. J Cell Sci 2016;129:12871292.

41 Rosenfeldt MT, O’Prey J, Morton JP, Nixon C, MacKay G, Mrowinska A, et al.: p53 status determines the role of autophagy in pancreatic tumour development. Nature 2013;504:296-300.

42 Escobar-Hoyos LF, Penson A, Kannan R, Cho H, Pan CH, Singh RK, et al.: Altered RNA Splicing by Mutant p53 Activates Oncogenic RAS Signaling in Pancreatic Cancer. Cancer Cell 2020;38:198-211.e198.

43 Butera G, Brandi J, Cavallini C, Scarpa A, Lawlor RT, Scupoli MT, et al.: The Mutant p53-Driven Secretome Has Oncogenic Functions in Pancreatic Ductal Adenocarcinoma Cells. Biomolecules 2020;10:884.

44 Wu C, Yang P, Liu B, Tang Y: Is there a CDKN2A-centric network in pancreatic ductal adenocarcinoma? Onco Targets Ther 2020;13:2551-2562.

45 Chen YW, Hsiao PJ, Weng CC, Kuo KK, Kuo TL, Wu DC, et al.: SMAD4 loss triggers the phenotypic changes of pancreatic ductal adenocarcinoma cells. BMC Cancer 2014;14:181.

46 Ahmed S, Bradshaw AD, Gera S, Dewan MZ, Xu R: The TGF- $\beta /$ Smad4 Signaling Pathway in Pancreatic Carcinogenesis and Its Clinical Significance. J Clin Med 2017;6:5.

47 Dardare J, Witz A, Merlin JL, Gilson P, Harlé A: SMAD4 and the TGF $\beta$ Pathway in Patients with Pancreatic Ductal Adenocarcinoma. Int J Mol Sci 2020;21:3534.

48 Doheny D, Manore SG, Wong GL, Lo HW: Hedgehog Signaling and Truncated GLI1 in Cancer. Cells 2020;9:2114.

49 Bausch D, Fritz S, Bolm L, Wellner UF, Fernandez-Del-Castillo C, Warshaw AL, et al.: Hedgehog signaling promotes angiogenesis directly and indirectly in pancreatic cancer. Angiogenesis 2020;23:479-492.

50 Carr RM, Duma N, McCleary-Wheeler AL, Almada LL, Marks DL, Graham RP, et al.: Targeting of the Hedgehog/GLI and mTOR pathways in advanced pancreatic cancer, a phase 1 trial of Vismodegib and Sirolimus combination. Pancreatology 2020;20:1115-1122.

51 Zhang Y, Morris JPt, Yan W, Schofield HK, Gurney A, Simeone DM, et al.: Canonical wnt signaling is required for pancreatic carcinogenesis. Cancer Res 2013;73:4909-4922.

52 Ram Makena M, Gatla H, Verlekar D, Sukhavasi S, M KP, K CP: Wnt/ $\beta$-Catenin Signaling: The Culprit in Pancreatic Carcinogenesis and Therapeutic Resistance. Int J Mol Sci 2019;20:4242.

53 Scholz A, Heinze S, Detjen KM, Peters M, Welzel M, Hauff P, et al.: Activated signal transducer and activator of transcription 3 (STAT3) supports the malignant phenotype of human pancreatic cancer. Gastroenterology 2003;125:891-905.

54 Wörmann SM, Song L, Ai J, Diakopoulos KN, Kurkowski MU, Görgülü K, et al.: Loss of P53 Function Activates JAK2-STAT3 Signaling to Promote Pancreatic Tumor Growth, Stroma Modification, and Gemcitabine Resistance in Mice and Is Associated With Patient Survival. Gastroenterology 2016;151:180-193.e112.

55 Gruber R, Panayiotou R, Nye E, Spencer-Dene B, Stamp G, Behrens A: YAP1 and TAZ Control Pancreatic Cancer Initiation in Mice by Direct Up-regulation of JAK-STAT3 Signaling. Gastroenterology 2016;151:526539.

56 Wang Y, Shen Y, Wang S, Shen Q, Zhou X: The role of STAT3 in leading the crosstalk between human cancers and the immune system. Cancer Lett 2018;415:117-128.

57 Zou S, Tong Q, Liu B, Huang W, Tian Y, Fu X: Targeting STAT3 in Cancer Immunotherapy. Mol Cancer 2020;19:145.

58 Nagathihalli NS, Castellanos JA, Shi C, Beesetty Y, Reyzer ML, Caprioli R, et al.: Signal Transducer and Activator of Transcription 3, Mediated Remodeling of the Tumor Microenvironment Results in Enhanced Tumor Drug Delivery in a Mouse Model of Pancreatic Cancer. Gastroenterology 2015;149:1932-1943. e1939.

59 Binenbaum Y, Na'ara S, Gil Z: Gemcitabine resistance in pancreatic ductal adenocarcinoma. Drug Resist Updat 2015;23:55-68.

60 Kleeff J, Korc M, Apte M, La Vecchia C, Johnson CD, Biankin AV, et al.: Pancreatic cancer. Nat Rev Dis Primers 2016;2:16022.

61 Vonderheide RH, Bear AS: Tumor-Derived Myeloid Cell Chemoattractants and T Cell Exclusion in Pancreatic Cancer. Front Immunol 2020;11:605619. 


\section{Cellular Physiology Cell Physiol Biochem 2021;55:61-90 \begin{tabular}{l|l|l} 
DOI: 10.33594/000000326 2021 The Author(s). Published by \\
\hline
\end{tabular} and BiOChemistry Published online: 29 January 2021 Cell Physiol Biochem Press GmbH\&Co. KG \\ Parrasia et al.: Targeting PDAC}

62 Olaoba OT, Ligali FC, Alabi ZO, Akinyemi AO, Ayinde KS: Of immune checkpoint maladies and remedies: The throwing of jabs in the oncogenic ring of PDAC. Biochim Biophys Acta Rev Cancer 2020;1875:188483.

63 Väyrynen SA, Zhang J, Yuan C, Väyrynen JP, Dias Costa A, Williams H, et al.: Composition, Spatial Characteristics, and Prognostic Significance of Myeloid Cell Infiltration in Pancreatic Cancer. Clin Cancer Res 2020; DOI: 10.1158/1078-0432.CCR-20-3141.

64 Gamradt P, De La Fouchardière C, Hennino A: Stromal Protein-Mediated Immune Regulation in Digestive Cancers. Cancers (Basel) 2021;13:146.

65 Cannon A, Thompson C, Hall BR, Jain M, Kumar S, Batra SK: Desmoplasia in pancreatic ductal adenocarcinoma: insight into pathological function and therapeutic potential. Genes Cancer 2018;9:78-86.

66 Wang S, Li Y, Xing C, Ding C, Zhang H, Chen L, et al.: Tumor microenvironment in chemoresistance, metastasis and immunotherapy of pancreatic cancer. Am J Cancer Res 2020;10:1937-1953.

67 Su T, Yang B, Gao T, Liu T, Li J: Polymer nanoparticle-assisted chemotherapy of pancreatic cancer. Ther Adv Med Oncol 2020;12:1758835920915978.

68 Ogawa Y, Masugi Y, Abe T, Yamazaki K, Ueno A, Fujii-Nishimura Y, et al.: Three distinct stroma types in human pancreatic cancer identified by image analysis of fibroblast subpopulations and collagen. Clin Cancer Res 2020;27:107-119.

69 Biondani G, Zeeberg K, Greco MR, Cannone S, Dando I, Dalla Pozza E, et al.: Extracellular matrix composition modulates PDAC parenchymal and stem cell plasticity and behavior through the secretome. FEBS J 2018;285:2104-2124.

70 Ying H, Dey P, Yao W, Kimmelman AC, Draetta GF, Maitra A, et al.: Genetics and biology of pancreatic ductal adenocarcinoma. Genes Dev 2016;30:355-385.

71 Kudo Y, Kohi S, Hirata K, Goggins M, Sato N: Hyaluronan activated-metabolism phenotype (HAMP) in pancreatic ductal adenocarcinoma. Oncotarget 2019;10:5592-5604.

72 Sato N, Kohi S, Hirata K, Goggins M: Role of hyaluronan in pancreatic cancer biology and therapy: Once again in the spotlight. Cancer Sci 2016;107:569-575.

73 Nagase H, Kudo D, Suto A, Yoshida E, Suto S, Negishi M, et al.: 4-Methylumbelliferone Suppresses Hyaluronan Synthesis and Tumor Progression in SCID Mice Intra-abdominally Inoculated With Pancreatic Cancer Cells. Pancreas 2017;46:190-197.

74 Yoshida E, Kudo D, Nagase H, Suto A, Shimoda H, Suto S, et al.: 4-Methylumbelliferone Decreases the Hyaluronan-rich Extracellular Matrix and Increases the Effectiveness of 5-Fluorouracil. Anticancer Res 2018;38:5799-5804.

75 Awaji M, Singh RK: Cancer-Associated Fibroblasts' Functional Heterogeneity in Pancreatic Ductal Adenocarcinoma. Cancers (Basel) 2019;11:290.

76 Hilmi M, Nicolle R, Bousquet C, Neuzillet C: Cancer-Associated Fibroblasts: Accomplices in the Tumor Immune Evasion. Cancers (Basel) 2020;12:2969.

77 Norton J, Foster D, Chinta M, Titan A, Longaker M: Pancreatic Cancer Associated Fibroblasts (CAF): UnderExplored Target for Pancreatic Cancer Treatment. Cancers (Basel) 2020;12:1347.

78 Bynigeri RR, Jakkampudi A, Jangala R, Subramanyam C, Sasikala M, Rao GV, et al.: Pancreatic stellate cell: Pandora's box for pancreatic disease biology. World J Gastroenterol 2017;23:382-405.

79 Fu Y, Liu S, Zeng S, Shen H: The critical roles of activated stellate cells-mediated paracrine signaling, metabolism and onco-immunology in pancreatic ductal adenocarcinoma. Mol Cancer 2018;17:62.

80 Farran B, Nagaraju GP: The dynamic interactions between the stroma, pancreatic stellate cells and pancreatic tumor development: Novel therapeutic targets. Cytokine Growth Factor Rev 2019;48:11-23.

81 Jin G, Hong W, Guo Y, Bai Y, Chen B: Molecular Mechanism of Pancreatic Stellate Cells Activation in Chronic Pancreatitis and Pancreatic Cancer. J Cancer 2020;11:1505-1515.

82 Nagathihalli NS, Castellanos JA, VanSaun MN, Dai X, Ambrose M, Guo Q, et al.: Pancreatic stellate cell secreted IL-6 stimulates STAT3 dependent invasiveness of pancreatic intraepithelial neoplasia and cancer cells. Oncotarget 2016;7:65982-65992.

83 Wu YS, Chung I, Wong WF, Masamune A, Sim MS, Looi CY: Paracrine IL-6 signaling mediates the effects of pancreatic stellate cells on epithelial-mesenchymal transition via Stat3/Nrf2 pathway in pancreatic cancer cells. Biochim Biophys Acta Gen Subj 2017;1861:296-306.

84 Sperb N, Tsesmelis M, Wirth T: Crosstalk between Tumor and Stromal Cells in Pancreatic Ductal Adenocarcinoma. Int J Mol Sci 2020;21:5486.

85 Chakravarthy A, Khan L, Bensler NP, Bose P, De Carvalho DD: TGF- $\beta$-associated extracellular matrix genes link cancer-associated fibroblasts to immune evasion and immunotherapy failure. Nat Commun 2018;9:4692. 


\section{Cellular Physiology Cell Physiol Biochem 2021;55:61-90 \begin{tabular}{l|l|l} 
DOI: 10.33594/000000326 2021 The Author(s). Published by \\
\hline
\end{tabular} and Biochemistry Published online: 29 January $2021 \quad$ Cell Physiol Biochem Press GmbH\&Co. KG \\ Parrasia et al.: Targeting PDAC}

86 Batlle E, Massagué J: Transforming Growth Factor- $\beta$ Signaling in Immunity and Cancer. Immunity 2019;50:924-940.

87 Saka D, Gökalp M, Piyade B, Cevik NC, Arik Sever E, Unutmaz D, et al.: Mechanisms of T-Cell Exhaustion in Pancreatic Cancer. Cancers (Basel) 2020;12:2274.

88 Stopa KB, Kusiak AA, Szopa MD, Ferdek PE, Jakubowska MA: Pancreatic Cancer and Its MicroenvironmentRecent Advances and Current Controversies. Int J Mol Sci 2020;21:2274.

89 Lambert A, Schwarz L, Borbath I, Henry A, Van Laethem JL, Malka D, et al.: An update on treatment options for pancreatic adenocarcinoma. Ther Adv Med Oncol 2019;11:1758835919875568.

90 Katayama ES, Hue JJ, Bajor DL, Ocuin LM, Ammori JB, Hardacre JM, et al.: A comprehensive analysis of clinical trials in pancreatic cancer: what is coming down the pike? Oncotarget 2020;11:3489-3501.

91 Álvarez P, Marchal JA, Boulaiz H, Carrillo E, Vélez C, Rodríguez-Serrano F, et al.: 5-Fluorouracil derivatives: a patent review. Expert Opin Ther Pat 2012;22:107-123.

92 Wilson PM, Danenberg PV, Johnston PG, Lenz HJ, Ladner RD: Standing the test of time: targeting thymidylate biosynthesis in cancer therapy. Nat Rev Clin Oncol 2014;11:282-298.

93 Diasio RB, Harris BE: Clinical pharmacology of 5-fluorouracil. Clin Pharmacokinet 1989;16:215-237.

94 Mackey JR, Mani RS, Selner M, Mowles D, Young JD, Belt JA, et al.: Functional nucleoside transporters are required for gemcitabine influx and manifestation of toxicity in cancer cell lines. Cancer Res 1998;58:43494357.

95 Ritzel MW, Ng AM, Yao SY, Graham K, Loewen SK, Smith KM, et al.: Recent molecular advances in studies of the concentrative Na+-dependent nucleoside transporter (CNT) family: identification and characterization of novel human and mouse proteins (hCNT3 and mCNT3) broadly selective for purine and pyrimidine nucleosides (system cib). Mol Membr Biol 2001;18:65-72.

96 Abbruzzese JL, Grunewald R, Weeks EA, Gravel D, Adams T, Nowak B, et al.: A phase I clinical, plasma, and cellular pharmacology study of gemcitabine. J Clin Oncol 1991;9:491-498.

97 Frese KK, Neesse A, Cook N, Bapiro TE, Lolkema MP, Jodrell DI, et al.: nab-Paclitaxel potentiates gemcitabine activity by reducing cytidine deaminase levels in a mouse model of pancreatic cancer. Cancer Discov 2012;2:260-269.

98 de Sousa Cavalcante L, Monteiro G: Gemcitabine: metabolism and molecular mechanisms of action, sensitivity and chemoresistance in pancreatic cancer. Eur J Pharmacol 2014;741:8-16.

99 Conroy T, Desseigne F, Ychou M, Bouché O, Guimbaud R, Bécouarn Y, et al.: FOLFIRINOX versus gemcitabine for metastatic pancreatic cancer. N Engl J Med 2011;364:1817-1825.

100 Lambert A, Gavoille C, Conroy T: Current status on the place of FOLFIRINOX in metastatic pancreatic cancer and future directions. Therap Adv Gastroenterol 2017;10:631-645.

101 Hajjar AH, Eid R, Haddad FG, Kourie HR: FOLFIRINOX: a new standard of care in the adjuvant setting of resectable pancreatic adenocarcinomas. Future Oncol 2019;15:1947-1950.

102 Von Hoff DD, Ervin T, Arena FP, Chiorean EG, Infante J, Moore M, et al.: Increased survival in pancreatic cancer with nab-paclitaxel plus gemcitabine. N Engl J Med 2013;369:1691-1703.

103 Yu Y, Zheng P, Chen Y, Wang B, Paul ME, Tao P, et al.: Advances and challenges of neoadjuvant therapy in pancreatic cancer. Asia Pac J Clin Oncol 2020; DOI: 10.1111/ajco.13504.

104 Franck C, Müller C, Rosania R, Croner RS, Pech M, Venerito M: Advanced Pancreatic Ductal Adenocarcinoma: Moving Forward. Cancers (Basel) 2020;12:1955.

105 Singh RR, O’Reilly EM: New Treatment Strategies for Metastatic Pancreatic Ductal Adenocarcinoma. Drugs 2020;80:647-669.

106 Oba A, Ho F, Bao QR, Al-Musawi MH, Schulick RD, Del Chiaro M: Neoadjuvant Treatment in Pancreatic Cancer. Front Oncol 2020;10:245.

107 de Jesus VHF, Camandaroba MPG, Calsavara VF, Riechelmann RP: Systematic review and meta-analysis of gemcitabine-based chemotherapy after FOLFIRINOX in advanced pancreatic cancer. Ther Adv Med Oncol 2020;12:1758835920905408.

108 Dreyer SB, Chang DK, Bailey P, Biankin AV: Pancreatic Cancer Genomes: Implications for Clinical Management and Therapeutic Development. Clin Cancer Res 2017;23:1638-1646.

109 Mueller S, Engleitner T, Maresch R, Zukowska M, Lange S, Kaltenbacher T, et al.: Evolutionary routes and KRAS dosage define pancreatic cancer phenotypes. Nature 2018;554:62-68.

110 Chuang HC, Huang PH, Kulp SK, Chen CS: Pharmacological strategies to target oncogenic KRAS signaling in pancreatic cancer. Pharmacol Res 2017;117:370-376. 


\section{Cellular Physiology Cell Physiol Biochem 2021;55:61-90 \begin{tabular}{l|l|l} 
and Biol: $10.33594 / 000000326$ & 2021 The Author(s). Published by
\end{tabular} and BiOchemistry Published online: 29 January $2021 \quad$ Cell Physiol Biochem Press GmbH\&Co. KG \\ Parrasia et al.: Targeting PDAC}

111 Nollmann FI, Ruess DA: Targeting Mutant KRAS in Pancreatic Cancer: Futile or Promising? Biomedicines 2020;8:281.

112 Sinn M, Bahra M, Liersch T, Gellert K, Messmann H, Bechstein W, et al.: CONKO-005: Adjuvant Chemotherapy With Gemcitabine Plus Erlotinib Versus Gemcitabine Alone in Patients After R0 Resection of Pancreatic Cancer: A Multicenter Randomized Phase III Trial. J Clin Oncol 2017;35:3330-3337.

113 Cohen SJ, O'Neil BH, Berlin J, Ames P, McKinley M, Horan J, et al.: A phase 1b study of erlotinib in combination with gemcitabine and nab-paclitaxel in patients with previously untreated advanced pancreatic cancer: an Academic Oncology GI Cancer Consortium study. Cancer Chemother Pharmacol 2016;77:693-701.

114 Carter CA, Rajan A, Keen C, Szabo E, Khozin S, Thomas A, et al.: Selumetinib with and without erlotinib in KRAS mutant and KRAS wild-type advanced nonsmall-cell lung cancer. Ann Oncol 2016;27:693-699.

115 Infante JR, Cohen RB, Kim KB, Burris HA, 3rd, Curt G, Emeribe U, et al.: A phase I dose-escalation study of Selumetinib in combination with Erlotinib or Temsirolimus in patients with advanced solid tumors. Invest New Drugs 2017;35:576-588.

116 Robson M, Im S-A, Senkus E, Xu B, Domchek SM, Masuda N, et al.: Olaparib for Metastatic Breast Cancer in Patients with a Germline BRCA Mutation. N Engl J Med 2017;377:523-533.

117 Moore K, Colombo N, Scambia G, Kim BG, Oaknin A, Friedlander M, et al.: Maintenance Olaparib in Patients with Newly Diagnosed Advanced Ovarian Cancer. N Engl J Med 2018;379:2495-2505.

118 Kim EJ, Sahai V, Abel EV, Griffith KA, Greenson JK, Takebe N, et al.: Pilot clinical trial of hedgehog pathway inhibitor GDC-0449 (vismodegib) in combination with gemcitabine in patients with metastatic pancreatic adenocarcinoma. Clin Cancer Res 2014;20:5937-5945.

119 Catenacci DV, Junttila MR, Karrison T, Bahary N, Horiba MN, Nattam SR, et al.: Randomized Phase Ib/ II Study of Gemcitabine Plus Placebo or Vismodegib, a Hedgehog Pathway Inhibitor, in Patients With Metastatic Pancreatic Cancer. J Clin Oncol 2015;33:4284-4292.

120 De Jesus-Acosta A, Sugar EA, O’Dwyer PJ, Ramanathan RK, Von Hoff DD, Rasheed Z, et al.: Phase 2 study of vismodegib, a hedgehog inhibitor, combined with gemcitabine and nab-paclitaxel in patients with untreated metastatic pancreatic adenocarcinoma. Br J Cancer 2020;122:498-505.

121 Borad MJ, Reddy SG, Bahary N, Uronis HE, Sigal D, Cohn AL, et al.: Randomized Phase II Trial of Gemcitabine Plus TH-302 Versus Gemcitabine in Patients With Advanced Pancreatic Cancer. J Clin Oncol 2015;33:14751481.

122 Sahin IH, Askan G, Hu ZI, O’Reilly EM: Immunotherapy in pancreatic ductal adenocarcinoma: an emerging entity? Ann Oncol 2017;28:2950-2961.

123 Johnson BA, 3rd, Yarchoan M, Lee V, Laheru DA, Jaffee EM: Strategies for Increasing Pancreatic Tumor Immunogenicity. Clin Cancer Res 2017;23:1656-1669.

124 Le DT, Durham JN, Smith KN, Wang H, Bartlett BR, Aulakh LK, et al.: Mismatch repair deficiency predicts response of solid tumors to PD-1 blockade. Science 2017;357:409-413.

125 Lupinacci RM, Goloudina A, Buhard O, Bachet JB, Maréchal R, Demetter P, et al.: Prevalence of Microsatellite Instability in Intraductal Papillary Mucinous Neoplasms of the Pancreas. Gastroenterology 2018;154:10611065.

126 Hu ZI, Shia J, Stadler ZK, Varghese AM, Capanu M, Salo-Mullen E, et al.: Evaluating Mismatch Repair Deficiency in Pancreatic Adenocarcinoma: Challenges and Recommendations. Clin Cancer Res 2018;24:1326-1336.

127 Laghi L, Beghelli S, Spinelli A, Bianchi P, Basso G, Di Caro G, et al.: Irrelevance of microsatellite instability in the epidemiology of sporadic pancreatic ductal adenocarcinoma. PLoS One 2012;7:e46002.

128 Mace TA, Shakya R, Pitarresi JR, Swanson B, McQuinn CW, Loftus S, et al.: IL-6 and PD-L1 antibody blockade combination therapy reduces tumour progression in murine models of pancreatic cancer. Gut 2018;67:320332.

129 Moral JA, Leung J, Rojas LA, Ruan J, Zhao J, Sethna Z, et al.: ILC2s amplify PD-1 blockade by activating tissuespecific cancer immunity. Nature 2020;579:130-135.

130 Coveler AL, Rossi GR, Vahanian NN, Link C, Chiorean EG: Algenpantucel-L immunotherapy in pancreatic adenocarcinoma. Immunotherapy 2016;8:117-125.

131 Intrado GlobeNewswire: NewLink Genetics Announces Results from Phase 3 IMPRESS Trial of Algenpantucel-L for Patients with Resected Pancreatic Cancer. URL: https://www.globenewswire.com/ news-release/2016/05/09/837878/0/en/NewLink-Genetics-Announces-Results-from-Phase-3-IMPRESSTrial-of-Algenpantucel-L-for-Patients-with-Resected-Pancreatic-Cancer.html. 


\section{Cellular Physiology Cell Physiol Biochem 2021;55:61-90 \begin{tabular}{l|l|l} 
and Biol: 10.33594/000000326 & (c)21 The Author(s). Published by
\end{tabular} and Biochemistry Published online: 29 January $2021 \quad$ Cell Physiol Biochem Press GmbH\&Co. KG \\ Parrasia et al.: Targeting PDAC}

132 Tempero MA, Reni M, Riess H, Pelzer U, O’Reilly EM, Winter JM, et al.: APACT: phase III, multicenter, international, open-label, randomized trial of adjuvant nab-paclitaxel plus gemcitabine (nab-P/G) vs gemcitabine (G) for surgically resected pancreatic adenocarcinoma. J Clin Oncol 2019;37:4000-4000.

133 Ko AH, Tempero MA, Shan YS, Su WC, Lin YL, Dito E, et al.: A multinational phase 2 study of nanoliposomal irinotecan sucrosofate (PEP02, MM-398) for patients with gemcitabine-refractory metastatic pancreatic cancer. Br J Cancer 2013;109:920-925.

134 Wang-Gillam A, Li CP, Bodoky G, Dean A, Shan YS, Jameson G, et al.: Nanoliposomal irinotecan with fluorouracil and folinic acid in metastatic pancreatic cancer after previous gemcitabine-based therapy (NAPOLI-1): a global, randomised, open-label, phase 3 trial. Lancet 2016;387:545-557.

135 Hingorani SR, Zheng L, Bullock AJ, Seery TE, Harris WP, Sigal DS, et al.: HALO 202: Randomized Phase II Study of PEGPH20 Plus Nab-Paclitaxel/Gemcitabine Versus Nab-Paclitaxel/Gemcitabine in Patients With Untreated, Metastatic Pancreatic Ductal Adenocarcinoma. J Clin Oncol 2018;36:359-366.

136 Ramanathan RK, McDonough SL, Philip PA, Hingorani SR, Lacy J, Kortmansky JS, et al.: Phase IB/II Randomized Study of FOLFIRINOX Plus Pegylated Recombinant Human Hyaluronidase Versus FOLFIRINOX Alone in Patients With Metastatic Pancreatic Adenocarcinoma: SWOG S1313. J Clin Oncol 2019;37:10621069.

137 Gao X, Deeb D, Liu Y, Liu P, Zhang Y, Shaw J, et al.: CDDO-Me inhibits tumor growth and prevents recurrence of pancreatic ductal adenocarcinoma. Int J Oncol 2015;47:2100-2106.

138 Zaccagnino A, Managò A, Leanza L, Gontarewitz A, Linder B, Azzolini M, et al.: Tumor-reducing effect of the clinically used drug clofazimine in a SCID mouse model of pancreatic ductal adenocarcinoma. Oncotarget 2017;8:38276-38293.

139 Liang C, Shi S, Meng Q, Liang D, Ji S, Zhang B, et al.: Complex roles of the stroma in the intrinsic resistance to gemcitabine in pancreatic cancer: where we are and where we are going. Exp Mol Med 2017;49:e406.

140 Bulle A, Dekervel J, Deschuttere L, Nittner D, Libbrecht L, Janky R, et al.: Gemcitabine Recruits M2-Type Tumor-Associated Macrophages into the Stroma of Pancreatic Cancer. Transl Oncol 2020;13:100743.

141 Hosein AN, Brekken RA, Maitra A: Pancreatic cancer stroma: an update on therapeutic targeting strategies. Nat Rev Gastroenterol Hepatol 2020;17:487-505.

142 Lee JJ, Perera RM, Wang H, Wu DC, Liu XS, Han S, et al.: Stromal response to Hedgehog signaling restrains pancreatic cancer progression. Proc Natl Acad Sci U S A 2014;111:E3091-3100.

143 Özdemir BC, Pentcheva-Hoang T, Carstens JL, Zheng X, Wu CC, Simpson TR, et al.: Depletion of carcinomaassociated fibroblasts and fibrosis induces immunosuppression and accelerates pancreas cancer with reduced survival. Cancer Cell 2014;25:719-734.

144 Rhim AD, Oberstein PE, Thomas DH, Mirek ET, Palermo CF, Sastra SA, et al.: Stromal elements act to restrain, rather than support, pancreatic ductal adenocarcinoma. Cancer Cell 2014;25:735-747.

145 Goldstein D, El-Maraghi RH, Hammel P, Heinemann V, Kunzmann V, Sastre J, et al.: nab-Paclitaxel plus gemcitabine for metastatic pancreatic cancer: long-term survival from a phase III trial. J Natl Cancer Inst 2015;107:dju413.

146 Heinemann V, Reni M, Ychou M, Richel DJ, Macarulla T, Ducreux M: Tumour-stroma interactions in pancreatic ductal adenocarcinoma: rationale and current evidence for new therapeutic strategies. Cancer Treat Rev 2014;40:118-128.

147 Von Hoff DD, Ramanathan RK, Borad MJ, Laheru DA, Smith LS, Wood TE, et al.: Gemcitabine plus nabpaclitaxel is an active regimen in patients with advanced pancreatic cancer: a phase I/II trial. J Clin Oncol 2011;29:4548-4554.

148 Giordano G, Pancione M, Olivieri N, Parcesepe P, Velocci M, Di Raimo T, et al.: Nano albumin boundpaclitaxel in pancreatic cancer: Current evidences and future directions. World J Gastroenterol 2017;23:5875-5886.

149 Zhao J, Wang H, Hsiao CH, Chow DS, Koay EJ, Kang Y, et al.: Simultaneous inhibition of hedgehog signaling and tumor proliferation remodels stroma and enhances pancreatic cancer therapy. Biomaterials 2018;159:215-228.

150 Rucki AA, Xiao Q, Muth S, Chen J, Che X, Kleponis J, et al.: Dual Inhibition of Hedgehog and c-Met Pathways for Pancreatic Cancer Treatment. Mol Cancer Ther 2017;16:2399-2409.

151 Ijichi H, Chytil A, Gorska AE, Aakre ME, Fujitani Y, Fujitani S, et al.: Aggressive pancreatic ductal adenocarcinoma in mice caused by pancreas-specific blockade of transforming growth factor-beta signaling in cooperation with active Kras expression. Genes Dev 2006;20:3147-3160. 


\section{Cellular Physiology Cell Physiol Biochem 2021;55:61-90 \begin{tabular}{l|l|l} 
and Biol: 10.33594/000000326 & 2021 The Author(s). Published by
\end{tabular} and Biochemistry Published online: 29 January 2021 Cell Physiol Biochem Press GmbH\&Co. KG \\ Parrasia et al.: Targeting PDAC}

152 Dosch AR, Dai X, Reyzer ML, Mehra S, Srinivasan S, Willobee BA, et al.: Combined Src/EGFR Inhibition Targets STAT3 Signaling and Induces Stromal Remodeling to Improve Survival in Pancreatic Cancer. Mol Cancer Res 2020;18:623-631.

153 Ramu I, Buchholz SM, Patzak MS, Goetze RG, Singh SK, Richards FM, et al.: SPARC dependent collagen deposition and gemcitabine delivery in a genetically engineered mouse model of pancreas cancer. EBioMedicine 2019;48:161-168.

154 Arpin CC, Mac S, Jiang Y, Cheng H, Grimard M, Page BD, et al.: Applying Small Molecule Signal Transducer and Activator of Transcription-3 (STAT3) Protein Inhibitors as Pancreatic Cancer Therapeutics. Mol Cancer Ther 2016;15:794-805.

155 Totiger TM, Srinivasan S, Jala VR, Lamichhane P, Dosch AR, Gaidarski AA, 3rd, et al.: Urolithin A, a Novel Natural Compound to Target PI3K/AKT/mTOR Pathway in Pancreatic Cancer. Mol Cancer Ther 2019;18:301-311.

156 Liu Y, Wang X, Zeng S, Zhang X, Zhao J, Zhang X, et al.: The natural polyphenol curcumin induces apoptosis by suppressing STAT3 signaling in esophageal squamous cell carcinoma. J Exp Clin Cancer Res 2018;37:303.

157 Jiang W, Zhao S, Xu L, Lu Y, Lu Z, Chen C, et al.: The inhibitory effects of xanthohumol, a prenylated chalcone derived from hops, on cell growth and tumorigenesis in human pancreatic cancer. Biomed Pharmacother 2015;73:40-47.

158 Froeling FE, Feig C, Chelala C, Dobson R, Mein CE, Tuveson DA, et al.: Retinoic acid-induced pancreatic stellate cell quiescence reduces paracrine Wnt- $\beta$-catenin signaling to slow tumor progression. Gastroenterology 2011;141:1486-1497, 1497.e1-14.

159 Carapuça EF, Gemenetzidis E, Feig C, Bapiro TE, Williams MD, Wilson AS, et al.: Anti-stromal treatment together with chemotherapy targets multiple signalling pathways in pancreatic adenocarcinoma. J Pathol 2016;239:286-296.

160 Kocher HM, Basu B, Froeling FEM, Sarker D, Slater S, Carlin D, et al.: Phase I clinical trial repurposing alltrans retinoic acid as a stromal targeting agent for pancreatic cancer. Nat Commun 2020;11:4841.

161 Han H, Hou Y, Chen X, Zhang P, Kang M, Jin Q, et al.: Metformin-Induced Stromal Depletion to Enhance the Penetration of Gemcitabine-Loaded Magnetic Nanoparticles for Pancreatic Cancer Targeted Therapy. J Am Chem Soc 2020;142:4944-4954.

162 Turaga RC, Sharma M, Mishra F, Krasinskas A, Yuan Y, Yang JJ, et al.: Modulation of Cancer-Associated Fibrotic Stroma by An Integrin $\alpha(v) \beta(3)$ Targeting Protein for Pancreatic Cancer Treatment. Cell Mol Gastroenterol Hepatol 2020;11:161-179.

163 Turaga RC, Yin L, Yang JJ, Lee H, Ivanov I, Yan C, et al.: Rational design of a protein that binds integrin $\alpha \mathrm{v} \beta 3$ outside the ligand binding site. Nat Commun 2016;7:11675.

164 Noel P, Von Hoff DD, Saluja AK, Velagapudi M, Borazanci E, Han H: Triptolide and Its Derivatives as Cancer Therapies. Trends Pharmacol Sci 2019;40:327-341.

165 Banerjee S, Modi S, McGinn O, Zhao X, Dudeja V, Ramakrishnan S, et al.: Impaired Synthesis of Stromal Components in Response to Minnelide Improves Vascular Function, Drug Delivery, and Survival in Pancreatic Cancer. Clin Cancer Res 2016;22:415-425.

166 Khanipour Roshan S, Spano AD, McKinney AM, Nascene DR: Potentially reversible acute cerebellar toxicity associated with Minnelide. Neuroradiology 2017;59:419-421.

167 Ramakrishnan P, Loh WM, Gopinath SCB, Bonam SR, Fareez IM, Mac Guad R, et al.: Selective phytochemicals targeting pancreatic stellate cells as new anti-fibrotic agents for chronic pancreatitis and pancreatic cancer. Acta Pharm Sin B 2020;10:399-413.

168 Kanai M, Yoshimura K, Asada M, Imaizumi A, Suzuki C, Matsumoto S, et al.: A phase I/II study of gemcitabine-based chemotherapy plus curcumin for patients with gemcitabine-resistant pancreatic cancer. Cancer Chemother Pharmacol 2011;68:157-164.

169 Pastorelli D, Fabricio ASC, Giovanis P, D'Ippolito S, Fiduccia P, Soldà C, et al.: Phytosome complex of curcumin as complementary therapy of advanced pancreatic cancer improves safety and efficacy of gemcitabine: Results of a prospective phase II trial. Pharmacol Res 2018;132:72-79.

170 Wang L, Liu X, Zhou Q, Sui M, Lu Z, Zhou Z, et al.: Terminating the criminal collaboration in pancreatic cancer: Nanoparticle-based synergistic therapy for overcoming fibroblast-induced drug resistance. Biomaterials 2017;144:105-118.

171 Kowolik CM, Lin M, Xie J, Overman LE, Horne DA: Attenuation of hedgehog/GLI signaling by NT1721 extends survival in pancreatic cancer. J Exp Clin Cancer Res 2019;38:431. 


\section{Cellular Physiology Cell Physiol Biochem 2021;55:61-90 \begin{tabular}{l|l|l} 
and Biol: 10.33594/000000326 2021 The Author(s). Published by & D
\end{tabular} and Biochemistry Published online: 29 January $2021 \quad$ Cell Physiol Biochem Press GmbH\&Co. KG \\ Parrasia et al.: Targeting PDAC}

172 Kowolik CM, Lin M, Xie J, Overman LE, Horne DA: NT1721, a novel epidithiodiketopiperazine, exhibits potent in vitro and in vivo efficacy against acute myeloid leukemia. Oncotarget 2016;7:86186-86197.

173 Annese T, Tamma R, Ruggieri S, Ribatti D: Angiogenesis in Pancreatic Cancer: Pre-Clinical and Clinical Studies. Cancers (Basel) 2019;11:381.

174 Di Maggio F, Arumugam P, Delvecchio FR, Batista S, Lechertier T, Hodivala-Dilke K, et al.: Pancreatic stellate cells regulate blood vessel density in the stroma of pancreatic ductal adenocarcinoma. Pancreatology 2016;16:995-1004.

175 Xiao Y, Qin T, Sun L, Qian W, Li J, Duan W, et al.: Resveratrol Ameliorates the Malignant Progression of Pancreatic Cancer by Inhibiting Hypoxia-induced Pancreatic Stellate Cell Activation. Cell Transplant 2020;29:963689720929987.

176 Hollinshead KER, Parker SJ, Eapen VV, Encarnacion-Rosado J, Sohn A, Oncu T, et al.: Respiratory Supercomplexes Promote Mitochondrial Efficiency and Growth in Severely Hypoxic Pancreatic Cancer. Cell Rep 2020;33:108231.

177 Denny WA, Wilson WR: Bioreducible mustards: a paradigm for hypoxia-selective prodrugs of diffusible cytotoxins (HPDCs). Cancer Metastasis Rev 1993;12:135-151.

178 Hunter FW, Wouters BG, Wilson WR: Hypoxia-activated prodrugs: paths forward in the era of personalised medicine. Br J Cancer 2016;114:1071-1077.

179 Sharma A, Arambula JF, Koo S, Kumar R, Singh H, Sessler JL, et al.: Hypoxia-targeted drug delivery. Chem Soc Rev 2019;48:771-813.

180 Spiegelberg L, Houben R, Niemans R, de Ruysscher D, Yaromina A, Theys J, et al.: Hypoxia-activated prodrugs and (lack of) clinical progress: The need for hypoxia-based biomarker patient selection in phase III clinical trials. Clin Transl Radiat Oncol 2019;15:62-69.

181 Wang Y, Shang W, Niu M, Tian J, Xu K: Hypoxia-active nanoparticles used in tumor theranostic. Int J Nanomedicine 2019;14:3705-3722.

182 Zhou M, Xie Y, Xu S, Xin J, Wang J, Han T, et al.: Hypoxia-activated nanomedicines for effective cancer therapy. Eur J Med Chem 2020;195:112274.

183 Hunter FW, Young RJ, Shalev Z, Vellanki RN, Wang J, Gu Y, et al.: Identification of P450 Oxidoreductase as a Major Determinant of Sensitivity to Hypoxia-Activated Prodrugs. Cancer Res 2015;75:4211-4223.

184 Sun JD, Liu Q, Wang J, Ahluwalia D, Ferraro D, Wang Y, et al.: Selective tumor hypoxia targeting by hypoxia-activated prodrug TH-302 inhibits tumor growth in preclinical models of cancer. Clin Cancer Res 2012;18:758-770.

185 Sun JD, Liu Q, Ahluwalia D, Li W, Meng F, Wang Y, et al.: Efficacy and safety of the hypoxia-activated prodrug TH-302 in combination with gemcitabine and nab-paclitaxel in human tumor xenograft models of pancreatic cancer. Cancer Biol Ther 2015;16:438-449.

186 Hajj C, Russell J, Hart CP, Goodman KA, Lowery MA, Haimovitz-Friedman A, et al.: A Combination of Radiation and the Hypoxia-Activated Prodrug Evofosfamide (TH-302) is Efficacious against a Human Orthotopic Pancreatic Tumor Model. Transl Oncol 2017;10:760-765.

187 Takakusagi Y, Matsumoto S, Saito K, Matsuo M, Kishimoto S, Wojtkowiak JW, et al.: Pyruvate induces transient tumor hypoxia by enhancing mitochondrial oxygen consumption and potentiates the anti-tumor effect of a hypoxia-activated prodrug TH-302. PLoS One 2014;9:e107995.

188 Wojtkowiak JW, Cornnell HC, Matsumoto S, Saito K, Takakusagi Y, Dutta P, et al.: Pyruvate sensitizes pancreatic tumors to hypoxia-activated prodrug TH-302. Cancer Metab 2015;3:2.

189 Kishimoto S, Brender JR, Chandramouli GVR, Saida Y, Yamamoto K, Mitchell JB, et al.: Hypoxia-Activated Prodrug Evofosfamide Treatment in Pancreatic Ductal Adenocarcinoma Xenografts Alters the Tumor Redox Status to Potentiate Radiotherapy. Antioxid Redox Signal 2020; DOI: 10.1089/ars.2020.8131.

190 Kulkarni P, Haldar MK, Karandish F, Confeld M, Hossain R, Borowicz P, et al.: Tissue-Penetrating, Hypoxia-Responsive Echogenic Polymersomes For Drug Delivery To Solid Tumors. Chemistry (Easton) 2018;24:12490-12494.

191 Kulkarni P, Haldar MK, You S, Choi Y, Mallik S: Hypoxia-Responsive Polymersomes for Drug Delivery to Hypoxic Pancreatic Cancer Cells. Biomacromolecules 2016;17:2507-2513.

192 Mamnoon B, Feng L, Froberg J, Choi Y, Sathish V, Mallik S: Hypoxia-Responsive, Polymeric Nanocarriers for Targeted Drug Delivery to Estrogen Receptor-Positive Breast Cancer Cell Spheroids. Mol Pharm 2020;17:4312-4322.

193 Anajafi T, Scott MD, You S, Yang X, Choi Y, Qian SY, et al.: Acridine Orange Conjugated Polymersomes for Simultaneous Nuclear Delivery of Gemcitabine and Doxorubicin to Pancreatic Cancer Cells. Bioconjug Chem 2016;27:762-771. 


\section{Cellular Physiology Cell Physiol Biochem 2021;55:61-90 \begin{tabular}{l|l|l} 
and Biol: 10.33594/000000326 & (c) 2021 The Author(s). Published by
\end{tabular} and Biochemistry Published online: 29 January $2021 \quad$ Cell Physiol Biochem Press GmbH\&Co. KG \\ Parrasia et al.: Targeting PDAC}

194 Karandish F, Froberg J, Borowicz P, Wilkinson JC, Choi Y, Mallik S: Peptide-targeted, stimuli-responsive polymersomes for delivering a cancer stemness inhibitor to cancer stem cell microtumors. Colloids Surf B Biointerfaces 2018;163:225-235.

195 Karandish F, Mamnoon B, Feng L, Haldar MK, Xia L, Gange KN, et al.: Nucleus-Targeted, Echogenic Polymersomes for Delivering a Cancer Stemness Inhibitor to Pancreatic Cancer Cells. Biomacromolecules 2018;19:4122-4132.

196 Nahire R, Haldar MK, Paul S, Ambre AH, Meghnani V, Layek B, et al.: Multifunctional polymersomes for cytosolic delivery of gemcitabine and doxorubicin to cancer cells. Biomaterials 2014;35:6482-6497.

197 Anajafi T, Yu J, Sedigh A, Haldar MK, Muhonen WW, Oberlander S, et al.: Nuclear Localizing PeptideConjugated, Redox-Sensitive Polymersomes for Delivering Curcumin and Doxorubicin to Pancreatic Cancer Microtumors. Mol Pharm 2017;14:1916-1928.

198 Xin X, Kumar V, Lin F, Kumar V, Bhattarai R, Bhatt VR, et al.: Redox-responsive nanoplatform for codelivery of miR-519c and gemcitabine for pancreatic cancer therapy. Sci Adv 2020;6:eabd6764.

199 Li Z, Zhao R, Wu X, Sun Y, Yao M, Li J, et al.: Identification and characterization of a novel peptide ligand of epidermal growth factor receptor for targeted delivery of therapeutics. FASEB J 2005;19:1978-1985.

200 Nong K, Zhang D, Chen C, Yang Y, Yang Y, Liu S, et al.: MicroRNA-519 inhibits hypoxia-induced tumorigenesis of pancreatic cancer by regulating immune checkpoint PD-L1. Oncol Lett 2020;19:1427-1433.

201 Jia Y, Xie J: Promising molecular mechanisms responsible for gemcitabine resistance in cancer. Genes Dis 2015;2:299-306.

202 He X, Wang J, Wei W, Shi M, Xin B, Zhang T, et al.: Hypoxia regulates ABCG2 activity through the activivation of ERK1/2/HIF- $1 \alpha$ and contributes to chemoresistance in pancreatic cancer cells. Cancer Biol Ther 2016;17:188-198.

203 Chaudhary AK, Mondal G, Kumar V, Kattel K, Mahato RI: Chemosensitization and inhibition of pancreatic cancer stem cell proliferation by overexpression of microRNA-205. Cancer Lett 2017;402:1-8.

204 Oweida AJ, Mueller AC, Piper M, Milner D, Van Court B, Bhatia S, et al.: Response to radiotherapy in pancreatic ductal adenocarcinoma is enhanced by inhibition of myeloid-derived suppressor cells using STAT3 anti-sense oligonucleotide. Cancer Immunol Immunother 2020; DOI: 10.1007/s00262-02002701-w.

205 Smith GP: Phage Display: Simple Evolution in a Petri Dish (Nobel Lecture). Angew Chem Int Ed Engl 2019;58:14428-14437.

206 Winter G: Harnessing Evolution to Make Medicines (Nobel Lecture). Angew Chem Int Ed Engl 2019;58:14438-14445.

207 Dissanayake S, Denny WA, Gamage S, Sarojini V: Recent developments in anticancer drug delivery using cell penetrating and tumor targeting peptides. J Control Release 2017;250:62-76.

208 D’Onofrio N, Caraglia M, Grimaldi A, Marfella R, Servillo L, Paolisso G, et al.: Vascular-homing peptides for targeted drug delivery and molecular imaging: meeting the clinical challenges. Biochim Biophys Acta 2014;1846:1-12.

209 Lu L, Qi H, Zhu J, Sun WX, Zhang B, Tang CY, et al.: Vascular-homing peptides for cancer therapy. Biomed Pharmacother 2017;92:187-195.

210 Ruoslahti E: Targeting tumor vasculature with homing peptides from phage display. Semin Cancer Biol 2000;10:435-442.

211 Arap W, Pasqualini R, Ruoslahti E: Cancer treatment by targeted drug delivery to tumor vasculature in a mouse model. Science 1998;279:377-380.

212 Kang S, Lee S, Park S: iRGD Peptide as a Tumor-Penetrating Enhancer for Tumor-Targeted Drug Delivery. Polymers (Basel) 2020;12:1906.

213 Lo JH, Hao L, Muzumdar MD, Raghavan S, Kwon EJ, Pulver EM, et al.: iRGD-guided Tumor-penetrating Nanocomplexes for Therapeutic siRNA Delivery to Pancreatic Cancer. Mol Cancer Ther 2018;17:2377-2388.

214 Zuo H: iRGD: A Promising Peptide for Cancer Imaging and a Potential Therapeutic Agent for Various Cancers. J Oncol 2019;2019:9367845.

215 Wang X, Wang H, Jiang K, Zhang Y, Zhan C, Ying M, et al.: Liposomes with cyclic RGD peptide motif triggers acute immune response in mice. J Control Release 2019;293:201-214.

216 Dumond A, Pagès G: Neuropilins, as Relevant Oncology Target: Their Role in the Tumoral Microenvironment. Front Cell Dev Biol 2020;8:662.

217 Napolitano V, Tamagnone L: Neuropilins Controlling Cancer Therapy Responsiveness. Int J Mol Sci 2019;20:2049. 


\section{Cellular Physiology Cell Physiol Biochem 2021;55:61-90 \begin{tabular}{l|l|l} 
and Biol: $10.33594 / 000000326$ & 2021 The Author(s). Published by
\end{tabular} and Biochemistry Published online: 29 January $2021 \quad$ Cell Physiol Biochem Press GmbH\&Co. KG \\ Parrasia et al.: Targeting PDAC}

218 He LH, He YL, Zuo WH, Kang Y, Xue H, Wang LY, et al.: Neuropilin1 silencing impairs the proliferation and migration of cells in pancreatic cancer. J Clin Lab Anal 2020;34:e23394.

219 Matkar PN, Jong ED, Ariyagunarajah R, Prud'homme GJ, Singh KK, Leong-Poi H: Jack of many trades: Multifaceted role of neuropilins in pancreatic cancer. Cancer Med 2018;7:5036-5046.

220 Jia G, Han Y, An Y, Ding Y, He C, Wang X, et al.: NRP-1 targeted and cargo-loaded exosomes facilitate simultaneous imaging and therapy of glioma in vitro and in vivo. Biomaterials 2018;178:302-316.

$221 \mathrm{Lu}$ L, Chen H, Hao D, Zhang X, Wang F: The functions and applications of A7R in anti-angiogenic therapy, imaging and drug delivery systems. Asian J Pharm Sci 2019;14:595-608.

222 Daly JL, Simonetti B, Klein K, Chen KE, Williamson MK, Antón-Plágaro C, et al.: Neuropilin-1 is a host factor for SARS-CoV-2 infection. Science 2020;370:861-865.

223 Graziadio A, Zanda M, Frau S, Fleming IN, Musolino M, Dall'Angelo S, et al.: NGR Tumor-Homing Peptides: Structural Requirements for Effective APN (CD13) Targeting. Bioconjug Chem 2016;27:1332-1340.

224 Tripodi AAP, Ranđelović I, Biri-Kovács B, Szeder B, Mező G, Tóvári J: In Vivo Tumor Growth Inhibition and Antiangiogenic Effect of Cyclic NGR Peptide-Daunorubicin Conjugates Developed for Targeted Drug Delivery. Pathol Oncol Res 2020;26:1879-1892.

225 Liu F, Li M, Liu C, Liu Y, Liang Y, Wang F, et al.: Tumor-specific delivery and therapy by double-targeted DTXCMCS-PEG-NGR conjugates. Pharm Res 2014;31:475-488.

226 Bouchet S, Tang R, Fava F, Legrand O, Bauvois B: The CNGRC-GG-D(KLAKLAK)2 peptide induces a caspaseindependent, Ca2+-dependent death in human leukemic myeloid cells by targeting surface aminopeptidase N/CD13. Oncotarget 2016;7:19445-19467.

227 Corti A, Gasparri AM, Sacchi A, Colombo B, Monieri M, Rrapaj E, et al.: NGR-TNF Engineering with an N-Terminal Serine Reduces Degradation and Post-Translational Modifications and Improves Its TumorTargeting Activity. Mol Pharm 2020;17:3813-3824.

228 Curnis F, Sacchi A, Borgna L, Magni F, Gasparri A, Corti A: Enhancement of tumor necrosis factor alpha antitumor immunotherapeutic properties by targeted delivery to aminopeptidase N (CD13). Nat Biotechnol 2000;18:1185-1190.

229 Porcellini S, Asperti C, Valentinis B, Tiziano E, Mangia P, Bordignon C, et al.: The tumor vessel targeting agent NGR-TNF controls the different stages of the tumorigenic process in transgenic mice by distinct mechanisms. Oncoimmunology 2015;4:e1041700.

230 Pastorino F, Brignole C, Di Paolo D, Nico B, Pezzolo A, Marimpietri D, et al.: Targeting liposomal chemotherapy via both tumor cell-specific and tumor vasculature-specific ligands potentiates therapeutic efficacy. Cancer Res 2006;66:10073-10082.

231 Lin W, Xie X, Deng J, Liu H, Chen Y, Fu X, et al.: Cell-penetrating peptide-doxorubicin conjugate loaded NGRmodified nanobubbles for ultrasound triggered drug delivery. J Drug Target 2016;24:134-146.

232 Zhu X, Lu N, Zhou Y, Xuan S, Zhang J, Giampieri F, et al.: Targeting Pancreatic Cancer Cells with PeptideFunctionalized Polymeric Magnetic Nanoparticles. Int J Mol Sci 2019;20:2988.

233 Dókus LE, Lajkó E, Ranđelović I, Mező D, Schlosser G, Kőhidai L, et al.: Phage Display-Based Homing Peptide-Daunomycin Conjugates for Selective Drug Targeting to PANC-1 Pancreatic Cancer. Pharmaceutics 2020;12:576.

234 Desmaële D, Gref R, Couvreur P: Squalenoylation: a generic platform for nanoparticular drug delivery. J Control Release 2012;161:609-618.

235 Réjiba S, Reddy LH, Bigand C, Parmentier C, Couvreur P, Hajri A: Squalenoyl gemcitabine nanomedicine overcomes the low efficacy of gemcitabine therapy in pancreatic cancer. Nanomedicine 2011;7:841-849.

236 Maksimenko A, Caron J, Mougin J, Desmaële D, Couvreur P: Gemcitabine-based therapy for pancreatic cancer using the squalenoyl nucleoside monophosphate nanoassemblies. Int J Pharm 2015;482:38-46.

237 Emamzadeh M, Desmaële D, Couvreur P, Pasparakis G: Dual controlled delivery of squalenoyl-gemcitabine and paclitaxel using thermo-responsive polymeric micelles for pancreatic cancer. J Mater Chem B 2018;6:2230-2239.

238 Rodríguez-Nogales C, Sebastián V, Irusta S, Desmaële D, Couvreur P, Blanco-Prieto MJ: A unique multidrug nanomedicine made of squalenoyl-gemcitabine and alkyl-lysophospholipid edelfosine. Eur J Pharm Biopharm 2019;144:165-173.

239 Chen Z, Zheng Y, Shi Y, Cui Z: Overcoming tumor cell chemoresistance using nanoparticles: lysosomes are beneficial for (stearoyl) gemcitabine-incorporated solid lipid nanoparticles. Int J Nanomedicine 2018;13:319-336. 


\section{Cellular Physiology Cell Physiol Biochem 2021;55:61-90 \begin{tabular}{l|l|l} 
and Biol: $10.33594 / 000000326$ & 2021 The Author(s). Published by
\end{tabular} and Biochemistry Published online: 29 January $2021 \quad$ Cell Physiol Biochem Press GmbH\&Co. KG \\ Parrasia et al.: Targeting PDAC}

240 Moysan E, Bastiat G, Benoit JP: Gemcitabine versus Modified Gemcitabine: a review of several promising chemical modifications. Mol Pharm 2013;10:430-444.

241 Maksimenko A, Mougin J, Mura S, Sliwinski E, Lepeltier E, Bourgaux C, et al.: Polyisoprenoyl gemcitabine conjugates self assemble as nanoparticles, useful for cancer therapy. Cancer Lett 2013;334:346-353.

242 Brusa P, Immordino ML, Rocco F, Cattel L: Antitumor activity and pharmacokinetics of liposomes containing lipophilic gemcitabine prodrugs. Anticancer Res 2007;27:195-199.

243 Immordino ML, Brusa P, Rocco F, Arpicco S, Ceruti M, Cattel L: Preparation, characterization, cytotoxicity and pharmacokinetics of liposomes containing lipophilic gemcitabine prodrugs. J Control Release 2004;100:331-346.

244 Sandoval MA, Sloat BR, Lansakara PD, Kumar A, Rodriguez BL, Kiguchi K, et al.: EGFR-targeted stearoyl gemcitabine nanoparticles show enhanced anti-tumor activity. J Control Release 2012;157:287-296.

245 Wang C, Zheng Y, Sand Oval MA, Valdes SA, Chen Z, Lansakara PD, et al.: Oral 4-(N)-stearoyl gemcitabine nanoparticles inhibit tumor growth in mouse models. Oncotarget 2017;8:89876-89886.

246 Zhu S, Li X, Lansakara PD, Kumar A, Cui Z: A nanoparticle depot formulation of 4-(N)-stearoyl gemcitabine shows a strong anti-tumour activity. J Pharm Pharmacol 2013;65:236-242.

247 Naguib YW, Lansakara PD, Lashinger LM, Rodriguez BL, Valdes S, Niu M, et al.: Synthesis, Characterization, and In Vitro and In Vivo Evaluations of 4-(N)-Docosahexaenoyl 2', 2'-Difluorodeoxycytidine with Potent and Broad-Spectrum Antitumor Activity. Neoplasia (New York, NY) 2016;18:33-48.

248 Valdes SA, Alzhrani RF, Rodriguez A, Lansakara PD, Thakkar SG, Cui Z: A solid lipid nanoparticle formulation of 4-(N)-docosahexaenoyl 2', 2'-difluorodeoxycytidine with increased solubility, stability, and antitumor activity. Int J Pharm 2019;570:118609.

249 Valdes SA, Alzhrani RF, Lansakara PD, Cui Z: Effect of a Solid Lipid Nanoparticle Formulation on the Bioavailability of 4-(N)-Docosahexaenoyl 2', 2'-Difluorodeoxycytidine After Oral Administration. AAPS PharmSciTech 2020;21:77.

250 Bildstein L, Dubernet C, Marsaud V, Chacun H, Nicolas V, Gueutin C, et al.: Transmembrane diffusion of gemcitabine by a nanoparticulate squalenoyl prodrug: an original drug delivery pathway. J Control Release 2010;147:163-170.

251 Bildstein L, Pili B, Marsaud V, Wack S, Meneau F, Lepêtre-Mouelhi S, et al.: Interaction of an amphiphilic squalenoyl prodrug of gemcitabine with cellular membranes. Eur J Pharm Biopharm 2011;79:612-620.

252 Sobot D, Mura S, Yesylevskyy SO, Dalbin L, Cayre F, Bort G, et al.: Conjugation of squalene to gemcitabine as unique approach exploiting endogenous lipoproteins for drug delivery. Nat Commun 2017;8:15678.

253 Guillaumond F, Bidaut G, Ouaissi M, Servais S, Gouirand V, Olivares O, et al.: Cholesterol uptake disruption, in association with chemotherapy, is a promising combined metabolic therapy for pancreatic adenocarcinoma. Proc Natl Acad Sci U S A 2015;112:2473-2478.

254 Sunami Y, Rebelo A, Kleeff J: Lipid Metabolism and Lipid Droplets in Pancreatic Cancer and Stellate Cells. Cancers (Basel) 2017;10:3.

255 Liu W, Mao Y, Zhang X, Wang Y, Wu J, Zhao S, et al.: RGDV-modified gemcitabine: a nano-medicine capable of prolonging half-life, overcoming resistance and eliminating bone marrow toxicity of gemcitabine. International journal of nanomedicine 2019;14:7263-7279.

256 Zhang X, Zhang J, Liu W, Wang Y, Wu J, Zhao S, et al.: Exploring the action of RGDV-gemcitabine on tumor metastasis, tumor growth and possible action pathway. Sci Rep 2020;10:15729.

257 Cox N, Kintzing JR, Smith M, Grant GA, Cochran JR: Integrin-Targeting Knottin Peptide-Drug Conjugates Are Potent Inhibitors of Tumor Cell Proliferation. Angew Chem Int Ed Engl 2016;55:9894-9897.

258 Vale N, Ferreira A, Fernandes I, Alves C, Araújo MJ, Mateus N, et al.: Gemcitabine anti-proliferative activity significantly enhanced upon conjugation with cell-penetrating peptides. Bioorg Med Chem Lett 2017;27:2898-2901.

259 Zakeri-Milani P, Mussa Farkhani S, Shirani A, Mohammadi S, Shahbazi Mojarrad J, Akbari J, et al.: Cellular uptake and anti-tumor activity of gemcitabine conjugated with new amphiphilic cell penetrating peptides. EXCLI J 2017;16:650-662.

260 Sayyad N, Vrettos EI, Karampelas T, Chatzigiannis CM, Spyridaki K, Liapakis G, et al.: Development of bioactive gemcitabine-D-Lys(6)-GnRH prodrugs with linker-controllable drug release rate and enhanced biopharmaceutical profile. Eur J Med Chem 2019;166:256-266.

261 Gaonkar RH, Baishya R, Paul B, Dewanjee S, Ganguly S, Debnath MC, et al.: Development of a peptidebased bifunctional chelator conjugated to a cytotoxic drug for the treatment of melanotic melanoma. Medchemcomm 2018;9:812-826. 


\section{Cellular Physiology Cell Physiol Biochem 2021;55:61-90 \begin{tabular}{ll|l} 
and Biol: 10.33594/000000326 & 2021 The Author(s). Published by
\end{tabular} and BIOChemistry Published online: 29 January $2021 \quad$ Cell Physiol Biochem Press GmbH\&Co. KG \\ Parrasia et al.: Targeting PDAC}

262 Han H, Wang J, Chen T, Yin L, Jin Q Ji J: Enzyme-sensitive gemcitabine conjugated albumin nanoparticles as a versatile theranostic nanoplatform for pancreatic cancer treatment. J Colloid Interface Sci 2017;507:217224.

263 Yu X, Song Y, Di Y, He H, Fu D, Jin C: Enhanced tumor targeting of cRGD peptide-conjugated albumin nanoparticles in the BxPC-3 cell line. Sci Rep 2016;6:31539.

264 Ji S, Xu J, Zhang B, Yao W, Xu W, Wu W, et al.: RGD-conjugated albumin nanoparticles as a novel delivery vehicle in pancreatic cancer therapy. Cancer Biol Ther 2012;13:206-215.

265 Song X, Lorenzi PL, Landowski CP, Vig BS, Hilfinger JM, Amidon GL: Amino acid ester prodrugs of the anticancer agent gemcitabine: synthesis, bioconversion, metabolic bioevasion, and hPEPT1-mediated transport. Mol Pharm 2005;2:157-167.

266 Tsume Y, Incecayir T, Song X, Hilfinger JM, Amidon GL: The development of orally administrable gemcitabine prodrugs with D-enantiomer amino acids: enhanced membrane permeability and enzymatic stability. Eur J Pharm Biopharm 2014;86:514-523.

267 Tsume Y, Drelich AJ, Smith DE, Amidon GL: Potential Development of Tumor-Targeted Oral Anti-Cancer Prodrugs: Amino Acid and Dipeptide Monoester Prodrugs of Gemcitabine. Molecules 2017;22:1322.

268 Thompson BR, Shi J, Zhu HJ, Smith DE: Pharmacokinetics of gemcitabine and its amino acid ester prodrug following intravenous and oral administrations in mice. Biochem Pharmacol 2020;180:114127.

269 Dong W, Cai Z, Pang J, Wang J, Tang N, Zhang W, et al.: Radiotherapy Enhancement for Human Pancreatic Carcinoma Using a Peptide-Gold Nanoparticle Hybrid. J Biomed Nanotechnol 2020;16:352-363.

270 Pal K, Al-Suraih F, Gonzalez-Rodriguez R, Dutta SK, Wang E, Kwak HS, et al.: Multifaceted peptide assisted one-pot synthesis of gold nanoparticles for plectin-1 targeted gemcitabine delivery in pancreatic cancer. Nanoscale 2017;9:15622-15634.

271 Valetti S, Maione F, Mura S, Stella B, Desmaële D, Noiray M, et al.: Peptide-functionalized nanoparticles for selective targeting of pancreatic tumor. J Control Release 2014;192:29-39.

272 Joyce JA, Laakkonen P, Bernasconi M, Bergers G, Ruoslahti E, Hanahan D: Stage-specific vascular markers revealed by phage display in a mouse model of pancreatic islet tumorigenesis. Cancer Cell 2003;4:393-403.

273 Wu L, Zhang F, Chen X, Wan J, Wang Y, Li T, et al.: Self-Assembled Gemcitabine Prodrug Nanoparticles Show Enhanced Efficacy against Patient-Derived Pancreatic Ductal Adenocarcinoma. ACS Appl Mater Interfaces 2020;12:3327-3340.

274 Bausch D, Thomas S, Mino-Kenudson M, Fernández-del CC, Bauer TW, Williams M, et al.: Plectin-1 as a novel biomarker for pancreatic cancer. Clin Cancer Res 2011;17:302-309.

275 Kelly KA, Bardeesy N, Anbazhagan R, Gurumurthy S, Berger J, Alencar H, et al.: Targeted nanoparticles for imaging incipient pancreatic ductal adenocarcinoma. PLoS Med 2008;5:e85.

276 Neoptolemos JP, Dunn JA, Stocken DD, Almond J, Link K, Beger H, et al.: Adjuvant chemoradiotherapy and chemotherapy in resectable pancreatic cancer: a randomised controlled trial. Lancet 2001;358:1576-1585.

277 Neoptolemos JP, Stocken DD, Friess H, Bassi C, Dunn JA, Hickey H, et al.: A randomized trial of chemoradiotherapy and chemotherapy after resection of pancreatic cancer. N Engl J Med 2004;350:12001210.

278 Oettle H, Neuhaus P, Hochhaus A, Hartmann JT, Gellert K, Ridwelski K, et al.: Adjuvant chemotherapy with gemcitabine and long-term outcomes among patients with resected pancreatic cancer: the CONKO-001 randomized trial. JAMA 2013;310:1473-1481.

279 Oettle H, Post S, Neuhaus P, Gellert K, Langrehr J, Ridwelski K, et al.: Adjuvant chemotherapy with gemcitabine vs observation in patients undergoing curative-intent resection of pancreatic cancer: a randomized controlled trial. JAMA 2007;297:267-277.

280 Neoptolemos JP, Stocken DD, Bassi C, Ghaneh P, Cunningham D, Goldstein D, et al.: Adjuvant chemotherapy with fluorouracil plus folinic acid vs gemcitabine following pancreatic cancer resection: a randomized controlled trial. JAMA 2010;304:1073-1081.

281 Sinn M, Liersch T, Riess H, Gellert K, Stübs P, Waldschmidt D, et al.: CONKO-006: A randomised doubleblinded phase IIb-study of additive therapy with gemcitabine + sorafenib/placebo in patients with R1 resection of pancreatic cancer - Final results. Eur J Cancer 2020;138:172-181.

282 Yoshitomi H, Togawa A, Kimura F, Ito H, Shimizu H, Yoshidome H, et al.: A randomized phase II trial of adjuvant chemotherapy with uracil/tegafur and gemcitabine versus gemcitabine alone in patients with resected pancreatic cancer. Cancer 2008;113:2448-2456.

283 Neoptolemos JP, Palmer DH, Ghaneh P, Psarelli EE, Valle JW, Halloran CM, et al.: Comparison of adjuvant gemcitabine and capecitabine with gemcitabine monotherapy in patients with resected pancreatic cancer (ESPAC-4): a multicentre, open-label, randomised, phase 3 trial. Lancet 2017;389:1011-1024. 